\title{
LA VIVIENDA SOCIAL COMO PATRIMONIO MODERNO: EL CASO DEL GRUPO “ANTONIO RUEDA" DE LA O.S.H. VIGENCIA Y CONSERVACIÓN
}

Figura A. 1965-1970, Grupo Antonio Rueda, imagen de época. Fuente: Hogar y Arquitectura 106 (1973)

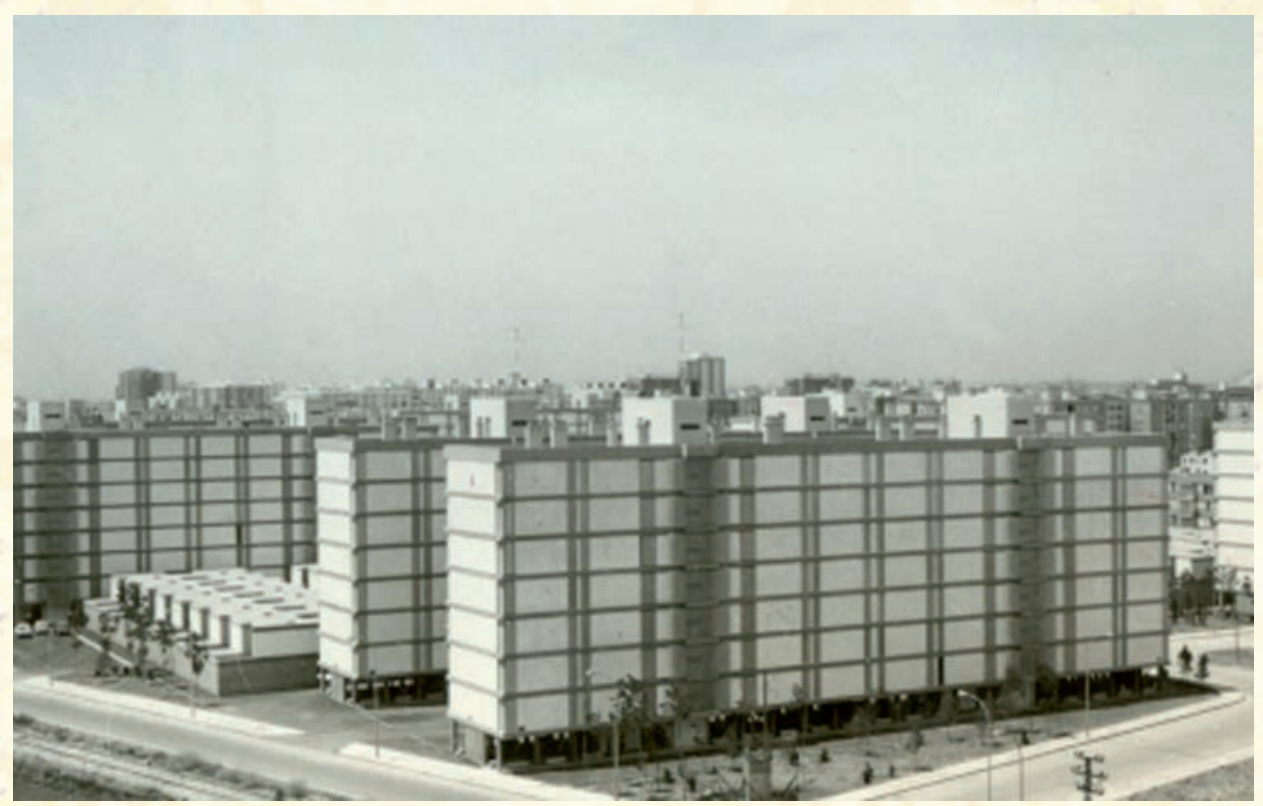

\section{RESUMEN}

El artículo centra su objeto de estudio en un caso concreto de arquitectura de vivienda social moderna, el Grupo "Antonio Rueda", un polígono de renta limitada de viviendas, obra de los arquitectos V. Valls, J. García Sanz y L. Mares, proyectado en 1965 y construido entre 1969-1970, con un total de I.002 viviendas, siendo una de las últimas intervenciones realizadas por la Obra Sindical del Hogar en la ciudad de Valencia.

Previo a revelar los valores propios y recursos formales que le caracterizan, se realiza una contextualización del panorama internacional en el que se propició la producción de viviendas para las clases sociales menos favorecidas a principios del siglo XX y como convergió con los postulados del Movimiento Moderno. Posteriormente se hace una breve aproximación a la producción de vivienda social iniciada en España a mediados de los cincuenta, acotada por la labor desempeñada por un organismo concreto, la "Obra Sindical del Hogar" del Instituto Nacional de Vivienda, y por aquellas realizaciones que fueron auténticamente modernas, ejemplarizándolo con el Poblado de "Caño Roto" en Madrid, cuyos arquitectos A. Vázquez de Castro y J. L. Iñíguez de Onzoño, supieron resolver con gran acierto acercándose a los postulados modernos.

\section{PALABRAS CLAVE}

Arquitectura Moderna, patrimonio moderno, modernidad, proyecto arquitectónico, vivienda social, Grupo de viviendas Antonio Rueda, Valencia. 


\section{THE SOCIAL HOUSING LIKE MODERN HERITAGE: THE CASE OF THE GROUP “ANTONIO RUEDA” OF THE O.S.H. FORCE AND CONSERVATION}

Amaya Martínez Marcos*

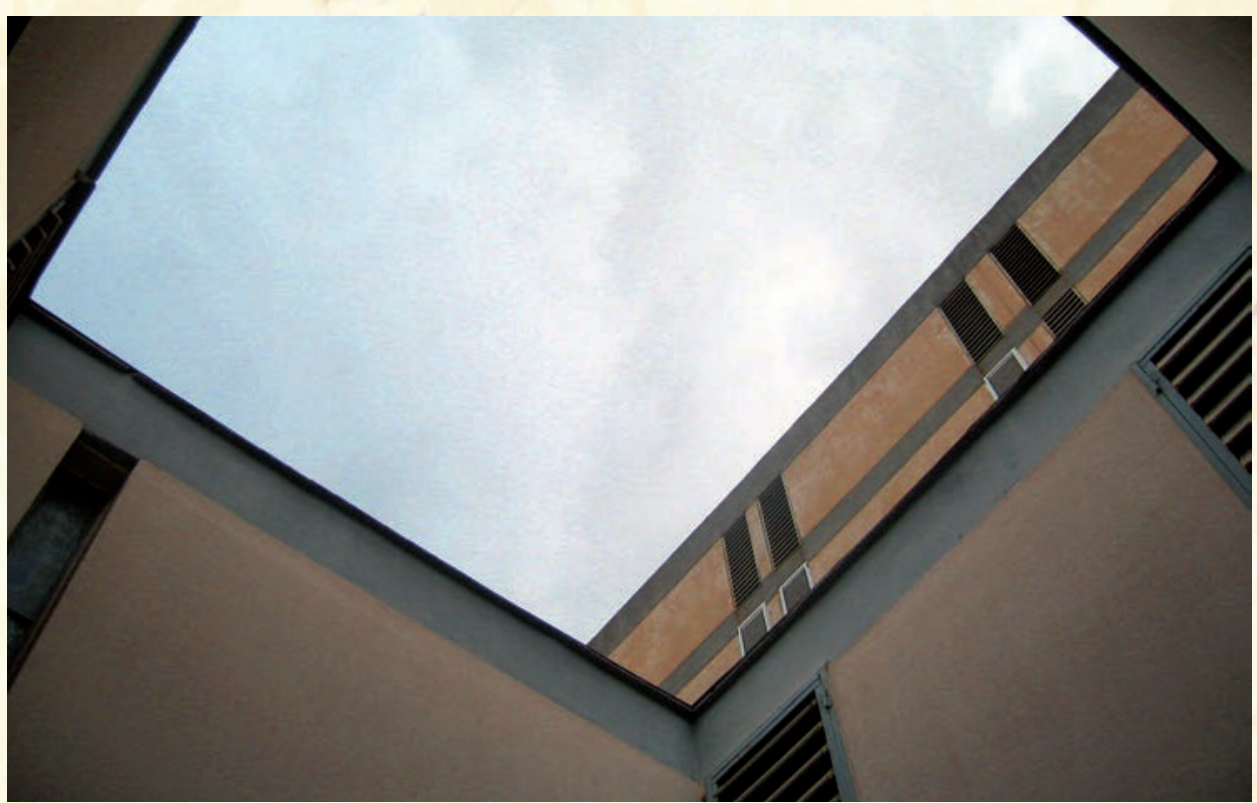

Arquitecta de la Universidad Politécnica de Valencia, 2005. Máster Oficial “Teoría y Práctica del Proyecto de Arquitectura" de la Universidad Politécnica de Cataluña, 2007. Candidata a Doctor por el Departamento de Proyectos Arquitectónicos de la UPC, con la Tesis Doctoral "La forma de la escuela moderna. La experiencia mediterránea en el ámbito Catalán y Valenciano desde las intenciones del GATEPAC a las realizaciones de 1956-1968". Su labor docente se inicia como becaria en el Departamento de Proyectos Arquitectónicos UPV-Valencia, 2003 2006. Desde el año 2008 es Becaria de Investigación de la Generalitat de Catalunya y miembro del Grupo de Investigación FORM, UPC-Barcelona. $\mathrm{Ha}$ participado, entre otros, en el proyecto de investigación financiado por el MICINN "Recuperación, valoración y ampliación del patrimonio moderno de la vivienda social colectiva en Argentina, Brasil, Chile y México" (2007-20I0).

\begin{abstract}
The article centers its object of study on a concrete case of architecture of social modern housing, the Group "Antonio Rueda", an neighborhood of limited revenue of housings, done by the architects V. Valls, J. García Sanz and L. Marés, projected in 1965 and constructed between 1969-1970, with a total of 1.002 housings, being one of the last interventions realized by the "Obra Sindical del Hogar" in the city of Valencia.
\end{abstract}

Previous to reveal the own values and formal resources that characterize it, there is a background done of the international panorama in which the housing production was favored to the underprivileged social classes at the beginning of the 20th century and as it converged with the postulates of the Modern Movement. Later a brief approximation was done to the production of social housing initiated in Spain in the middle of the fifties, bounded by the work done by a particular organism, the "Obra Sindical del Hogar" of the "Instituto Nacional de la Vivienda", and for those achievements that were truly modern, exemplified with the Settlement of "Caño Roto" in Madrid, whose architects A. Vázquez de Castro and J. L. Iñiguez de Onzoño, could resolve with great success approaching the modern principles.

\title{
KEY WORDS
}

Modern Architecture, modern patrimony, modernity, architectural design, social housing, Housing Group “Antonio Rueda”, Valencia. 


\section{INTRODUCCIÓN}

El artículo surge a partir de la conferencia impartida "La OSH: Un recorrido por el grupo de Viviendas Antonio Rueda", presentada el 7 de Octubre de 2009, en el "6 Seminario de Arquitectura moderna: La vivienda social en América Latina"| celebrado en la Universidad Politécnica de Cataluña. El artículo reestructura la conferencia, amplía su contenido y contexto, fruto de las investigaciones posteriores llevadas a cabo en el ámbito de la vivienda social moderna. ${ }^{2}$

Del mismo modo que, en el " $5^{\circ}$ Seminario de Arquitectura moderna: Seminario sobre la conservación y futuro de la vivienda social moderna"3, se realizó una mirada cruzada entre las realizaciones de América Latina ${ }^{4}$ y España, centradas estas últimas en casos primerizos de Barcelona como la Casa Bloc y los polígonos de los años 50 y 60 como Montbau o La Mina, en la segunda jornada del $6^{\circ}$ Seminario se presentaron nuevas investigaciones de casos latinoamericanos y de España como es el caso del "Grupo de viviendas Antonio Rueda" en la ciudad de Valencia. Este proceder permitió establecer sinergias, a la vez que ampliar la investigación, entre la producción de vivienda social llevada a cabo durante el periodo 1950-1970 en los diversos territorios estudiados.

\section{SOBRE EL ORIGEN DE LA VIVIENDA SOCIAL}

El concepto de "vivienda social", también acuñada "obrera", "proletaria" o "de interés popular", surge a inicios del siglo XX como respuesta al problema del alojamiento que estaban experimentando las ciudades a partir de la revolución industrial y más concretamente desde su consolidación. Esta problemática, con independencia a las políticas estatales o de iniciativa privada, despertó el interés de los arquitectos modernos por la resolución de esta tipología edificatoria acorde a las nuevas necesidades de la población. Así, en I923, Le Corbusier anunciaría:

"La Arquitectura se ocupa de la casa ordinaria y corriente, para hombres normales y corrientes. Deja de lado los palacios. He aquí un signo de los tiempos."

La premisa establecida no era exclusivamente la de resolver el problema de una vivienda digna acorde a las necesidades del momento, sino que además habría que llegar más lejos y resolver el problema de la ciudad y de su planificación. La vivienda se convierte así en una "célula primaria" de un dispositivo de mayor escala, la ciudad, como revelaría Gropius en 1925:

I El $6^{\circ}$ seminario, organizado por el Grupo Form, estuvo centrado en la producción de vivienda social mexicana y contó con la presencia del Dr. Arq. Ernesto Alva Martínez, profesor e investigador de la UNAM, y especialista en el estudio de la vivienda social mexicana. Se inauguró la exposición "Arquitectura Moderna. Vivienda Social en América Latina" que, hasta la actualidad, ha sido expuesta en Barcelona en la UPC y en la Universidad La Salle; en Brasil en la Universidad de Porto Alegre; en Argentina en la Sociedad Central de Arquitectos y en la Universidad de Palermo; en Chile en la Pontificia Universidad Católica. Se publicó el libro "Vivienda social moderna. México 1947-1967. Colección Documentos de Arquitectura Moderna en América Latina", Barcelona: Grupo Form, DPA-UPC, 2009

2 Durante el periodo 2007-20 I 0, los investigadores del Grupo Form bajo la coordinación de Teresa Rovira han llevado a cabo el proyecto de investigación titulado "Recuperación, valoración y aplicación del patrimonio moderno de la vivienda social colectiva en Argentina, Brasil, Chile y México" y cuyas conclusiones finales han quedado recogidas en el libro "Documentos de Arquitectura moderna en América Latina 1950-1965. Vivienda social en Argentina, Brasil, Chile y México. Cuarto volumen.", Barcelona, Grupo Form, Casa América de Catalunya, 2010

3 Organizado por el grupo Form, se celebró en Barcelona en Mayo de 2008 en la sede de Casa América de Cataluña. Se publicó el Libro "Seminario sobre la conservación y futuro de la vivienda social moderna. Recopilación de documentos", Barcelona: Grupo Form, DPA-UPC, 2008

4 Con casos de Argentina (Adriana Collado, UNL), Brasil (Nabil Bonduki, FAU-USP), Chile (Horacio Torrent, PUC) y México (Ernesto Alva, UNAM)

5 Le Corbusier. Hacia una Arquitectura. Barcelona: Ed. Apóstrofe S.L., 1998. [Vers une architecture, 1923.] 
"La casa de vivienda considerada como célula de base de una unidad superior, que es la calle, representa un órgano de grupo tipo. La unidad de las células entre sí exige una elaboración formal. En la medida en que constituye un modelo más acabado que cualquiera de los prototipos de los que deriva, un estándar admitido es siempre el denominador formal común de todo un periodo. La unificación de los componentes arquitectónicos debería contribuir a dar a nuestras ciudades esa homogeneidad saludable que es el signo propio de una cultura urbana superior.

Mi idea de arquitecto como coordinador -cuyo papel consiste en reducir a un común denominador los problemas plásticos, técnicos, sociales y económicos que plantea la construcción- me llevó ineludiblemente del estudio de las funciones de la vivienda al de las funciones de la calle, y de la de las calles a las de la ciudad."

El interés despertado por la vivienda queda patente al organizar en 1929 el II Congreso CIAM, celebrado en Frankfurt, en torno al estudio de la Vivienda Mínima "Existenzminimun". El énfasis surgió en la proposición de una nueva tipología, el bloque de vivienda colectivo y aislado en el que se enfatizaba el uso de la tipología en dúplex y el acceso por corredor y con el que se pretendía liberar la mayor parte de suelo para que éste entrase a formar parte de la actividad diaria de sus habitantes $y$, en definitiva, de la ciudad. Pero el concepto de "mínima" no venía definido en relación a unas dimensiones mínimas de vivienda, sino como una variable en función del número de habitantes, de las nuevas funciones y usos y por lo tanto, de los nuevos comportamientos.

La experiencia de la vanguardia de los años 20 con las Siedlung alemanas y posteriormente los principios propuestos en el IV CIAM celebrado en Atenas en 1933, quedarían recogidos por le Corbusier en la "Carta de Atenas", publicada en 194I, en la que se establecían las cuatro funciones básicas para el ciudadano: residencia, tiempo libre, trabajo y circulación. La ciudad pues debía dar respuesta a estas funciones básicas y el modelo propuesto era el de una ciudad de estructura abierta, con bloques aislados que permitiesen liberar el suelo para generar áreas libres $y$ arboladas por las que discurriesen separadas las circulaciones peatonales y rodadas. La ubicación de los equipamientos básicos debían estar vinculados a las unidades de agrupación y los generales en relación a un orden mayor, el de la propia ciudad.

A nivel nacional, en 1930, se crea en Barcelona un grupo afín a las nuevas ideologías promulgadas por los CIAM, el GATCPAC (Grup d'Arquitectes i Tècnics Catalans per el Progrès de l'Arquitectura Contemporània), cuyos miembros pronto entrarían en contacto con las vanguardias europeas, convirtiéndose el joven arquitecto Josep Lluis Sert en uno de sus más fervientes seguidores. En 1932 se constituye el GATEPAC a nivel nacional, pasando a ser la sección española del CIRPAC (Comité International pour la Résolution des Problèmes d'Architecture Contemporaine) y por lo tanto, participarían activamente en los Congresos CIAM.

Durante el periodo de la II República Española (1931-1939) se desarrollan iniciativas sociales, apoyadas por los organismos estatales, para la resolución de una vivienda digna y cuya máxima expresión quedó materializada con "La Casa Bloc" que Sert, junto a Joan B. Subirana y Josep Torres Clavé construyeron en la ciudad de Barcelona entre 1932 y 1936, bajo el amparo de la Generalitat de Catalunya. (Fig. I. I) La casa Bloc se proyecta como un modelo de casa obrera que partía de una unidad básica, la vivienda, y que en su conjunto resolvía una serie de servicios y equipamientos como requisitos sociales esenciales de la

6 Gropius, Walter. Internationale Architektur. Munich: Bauhaus Bücher, A. Langen, 1925 
Figura I.1. 1932-1936. Casa Bloc y presentación del proyecto en 1933

Figura I.2. 1933, Plan Maciá, montaje de la propuesta
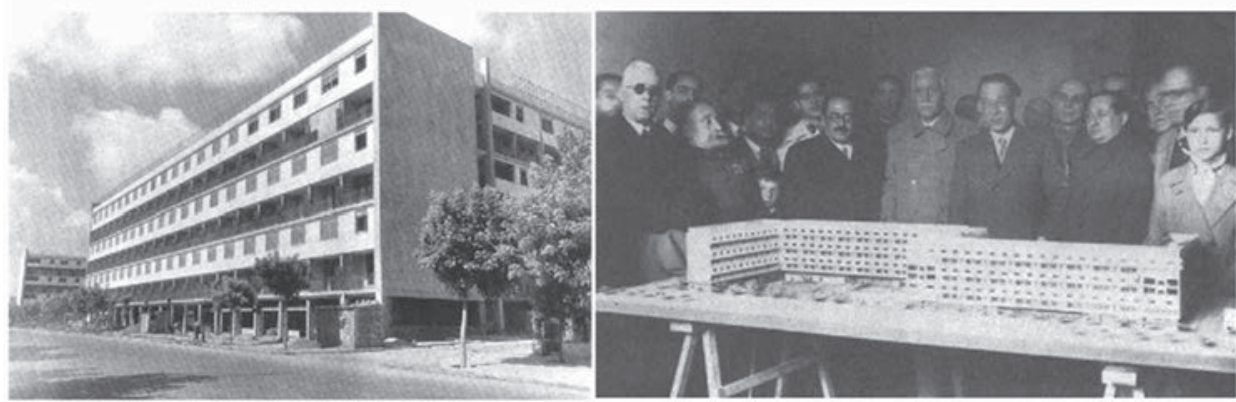

nueva sociedad. La Casa Bloc aparece como una combinación de bloques en "L", en 7 niveles y con accesos por corredor a las viviendas de tipo dúplex cada dos, optimizando así la superficie destinada a elementos comunes. (Fig. I.2) El modelo utilizado pretendía ser el tipo capaz de generar un nuevo modelo de crecimiento de ciudad: una ciudad de tipología abierta, como promulgaba el Plan Maciá, que junto a Le Corbusier, Sert proyectaba en estos años para la remodelación y ampliación de la ciudad de Barcelona.(Fig. I.3)
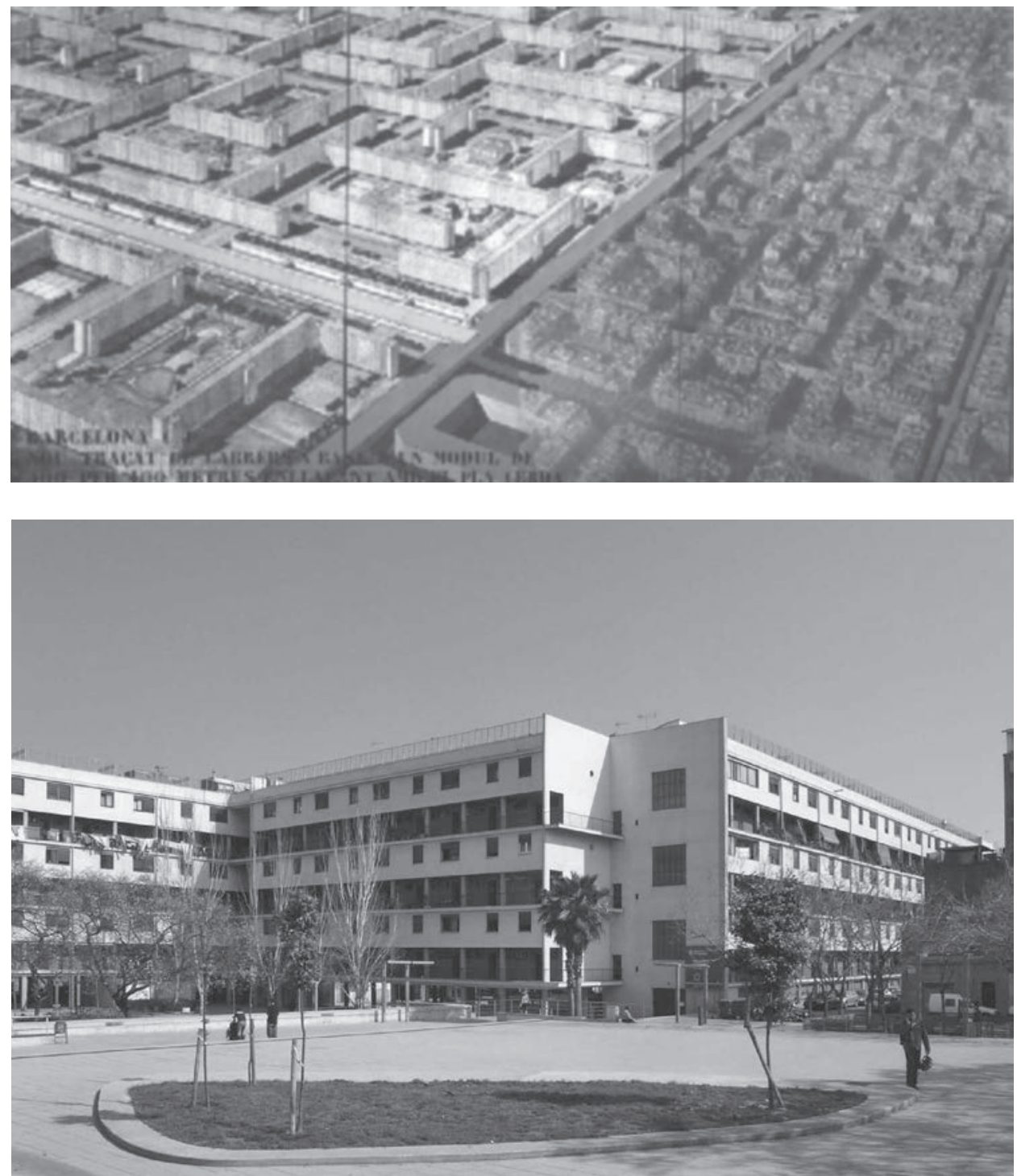

Figura 1 3. 1932-1936, Casa Bloc. Foto: A. Solano, 2007 
España entraría en un proceso de recesión tras la victoria franquista de la Guerra Civil, recordemos que Sert y los arquitectos más comprometidos con la modernidad deben exiliarse, y no sería hasta inicios de los 50, con el ingreso de España en la UNESCO y hasta 1955 con el ingreso en la $\mathrm{ONU}$, que se iniciaría una nueva apertura económica al exterior, que permitiría a la generación de nuevos arquitectos retomar las arquitecturas comprometidas con la modernidad. Además es coincidente que las políticas sociales buscaran una solución al problema de hacinamiento que estaban experimentando las principales ciudades, como Madrid y Barcelona, con la llegada de las propias migraciones internas de la población en busca de trabajo.

\section{LAS PRIMERAS PROPUESTAS MODERNAS DE LA OSH: EL POBLADO DE CAÑO ROTO EN MADRID}

La Obra Sindical del Hogar ${ }^{7}$, fue un organismo del franquismo, creado en I 94 I bajo la dependencia del Ministerio de Gobernación, para la coordinación de viviendas de renta baja, que llegó a construir hasta 300.000 viviendas por todo el país, en sus 24 años de existencia. (Fig. 2. I)

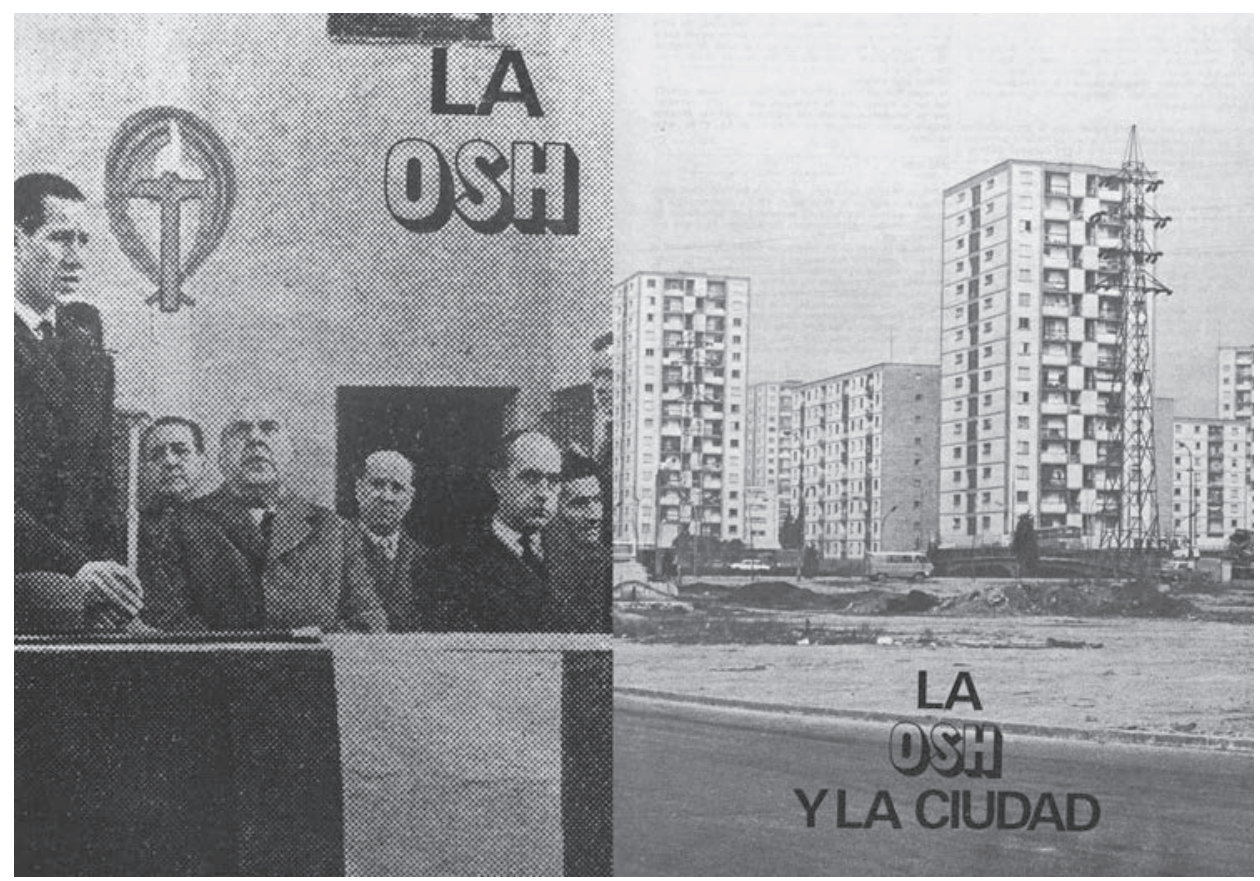

A mediados de los años 50 su preocupación principal era resolver la creación de viviendas sociales para las clases trabajadoras que llegaban a la ciudad lo que conllevaba un rápido proceso de concentración urbana y que, por consiguiente, generaba la creación de poblados chabolistas, como se acuñó en Madrid, o barraquistas, como se denominó en Barcelona. Se generaban ciudades informales y la $\mathrm{OSH}$ buscaba solucionar el problema que estas acarreaban:

"Sus funciones más específicas son:

a) Constructora del I.N.V.

b) Divulgar las facilidades de la Ley de Viviendas Protegidas entre beneficiarios económicamente débiles.
Figura 2. I. Artículos sobre la OSH en Cuadernos de Arquitectura y Urbanismo 105 (1974)

7 Revista Hogar y Arquitectura No. 100, 1972 
c) Planificar la vivienda obrera de renta reducida estableciendo sus condiciones técnicas.

d) Fomentar la construcción de viviendas, contribuyendo a su financiación con préstamos y anticipos a los futuros beneficiarios.

e) Recoger y encauzar la iniciativa privada, individual y empresarial, en orden a la construcción de viviendas protegidas, especialmente las de menor coste y renta de amortización.

f) Concertar con instituciones públicas de crédito y ahorro convenios especiales para financiar viviendas protegidas.

g) Estudiar técnicas para obtener mayor rendimiento de los aspectos técnicos y financieros de la construcción de viviendas." 8

La idea de la OSH era construir con mínimas dimensiones, mínimos estándares y mínimos costes, y no es hasta 1955 que Luis Valero, director del Instituto Nacional de la Vivienda, consigue la aprobación del Reglamento de la Ley de Viviendas de Renta Limitada. Un primer marco legal para la realización de los nuevos poblados que se comenzarían a realizar a partir de 1956, y que establecía unas normas que dotasen de una calidad mínima a las nuevas viviendas.

La aparición de diferentes organismos con competencia en materia de vivienda social, generó un caos legal y burocrático que conllevó, en 1957, a la creación del Ministerio de Vivienda. Se pretendía establecer un orden en materia urbanística a través de un Plan del suelo, que controlase no sólo la iniciativa privada sino la pública.

Aún así, el nivel de calidad de las viviendas nunca llegó a ser homogéneo, tan sólo en algunos casos se obedecía a una buena construcción y a unos estándares aceptables. En la mayoría, se produjo un rápido deterioro material y degradación de las condiciones de habitabilidad, debido al escaso mantenimiento.(Fig. 2.2)

Figura 2.2. Artículos sobre la OSH en Cuadernos de Arquitectura y Urbanismo 105 (1974)

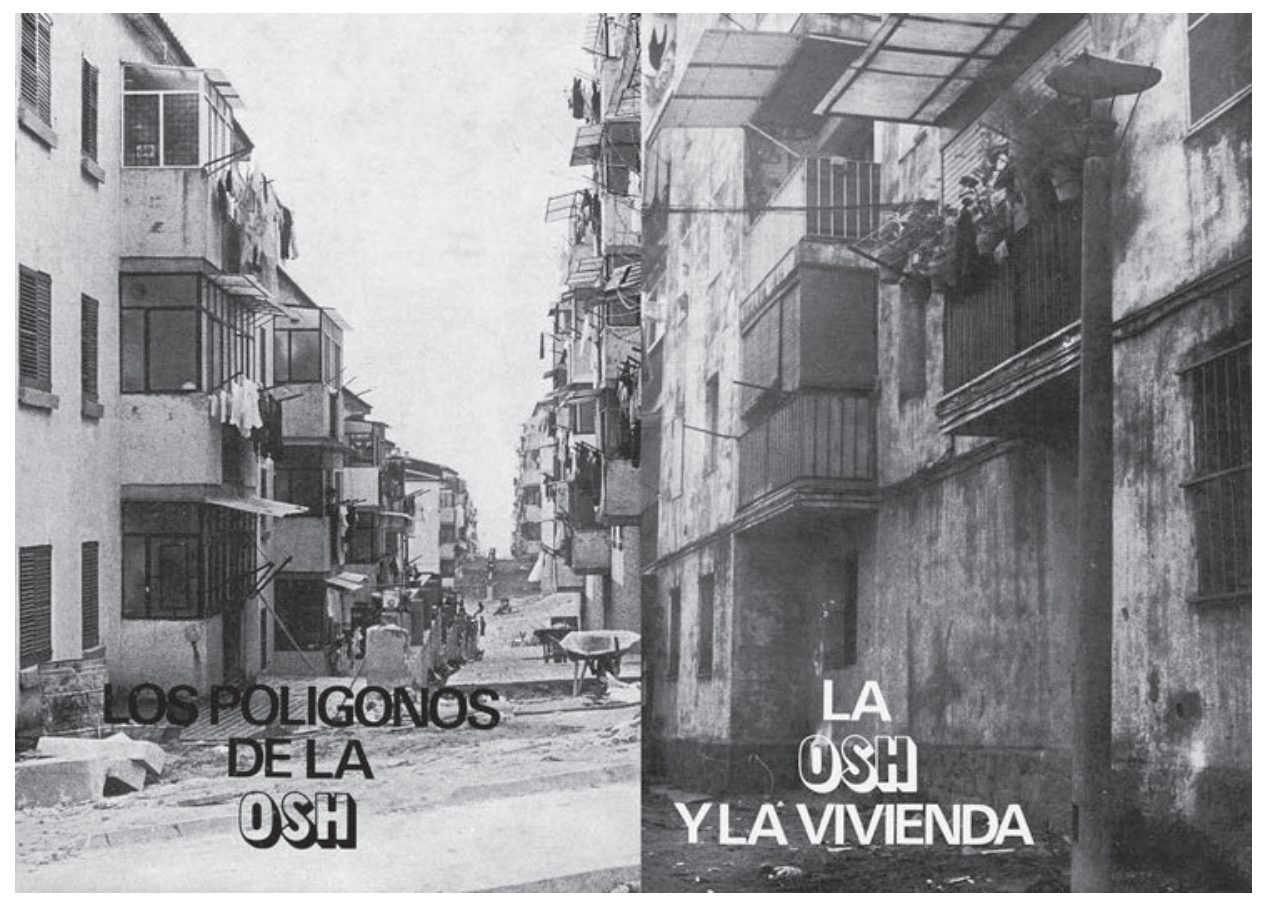

$8 \quad$ Revista Cuadernos de Arquitectura y Urbanismo No. 105, 1974; p. 37 
Sin embargo, estos conjuntos tuvieron grandes efectos en los mecanismos de crecimiento y expansión urbana de la ciudad. La inserción urbanística generalmente se daba en localizaciones periféricas con el problema de déficits infraestructurales y la carencia de equipamientos. El éxito quedaba relegado a una buena integración urbana y a una planificación coherente, que no todos lograron resolver.

En los años 60, el papel de la OSH disminuye debido a la entrada de la iniciativa privada en el mercado de la construcción de viviendas, al convertirse éste en un negocio muy rentable. De hecho, desde el Estado se animaba a su intervención directa, para reducir así los costes que el Estado invertía.

El papel de la OSH fue transmitido por la revista Hogar y Arquitectura, que desde su aparición en 1955 y hasta 1977 dedicó una atención preferente a la vivienda de tipo social en sus 122 números. La revista mantuvo un intercambio con las más destacadas y conocidas revistas técnicas como l'Architecture d'Ajourd'hui, lo que permitió que las realizaciones españolas de la época se difundiesen por Europa, América y Extremo Oriente. Sólo en Argentina contaba con 200 suscriptores.(Fig. 2.3)

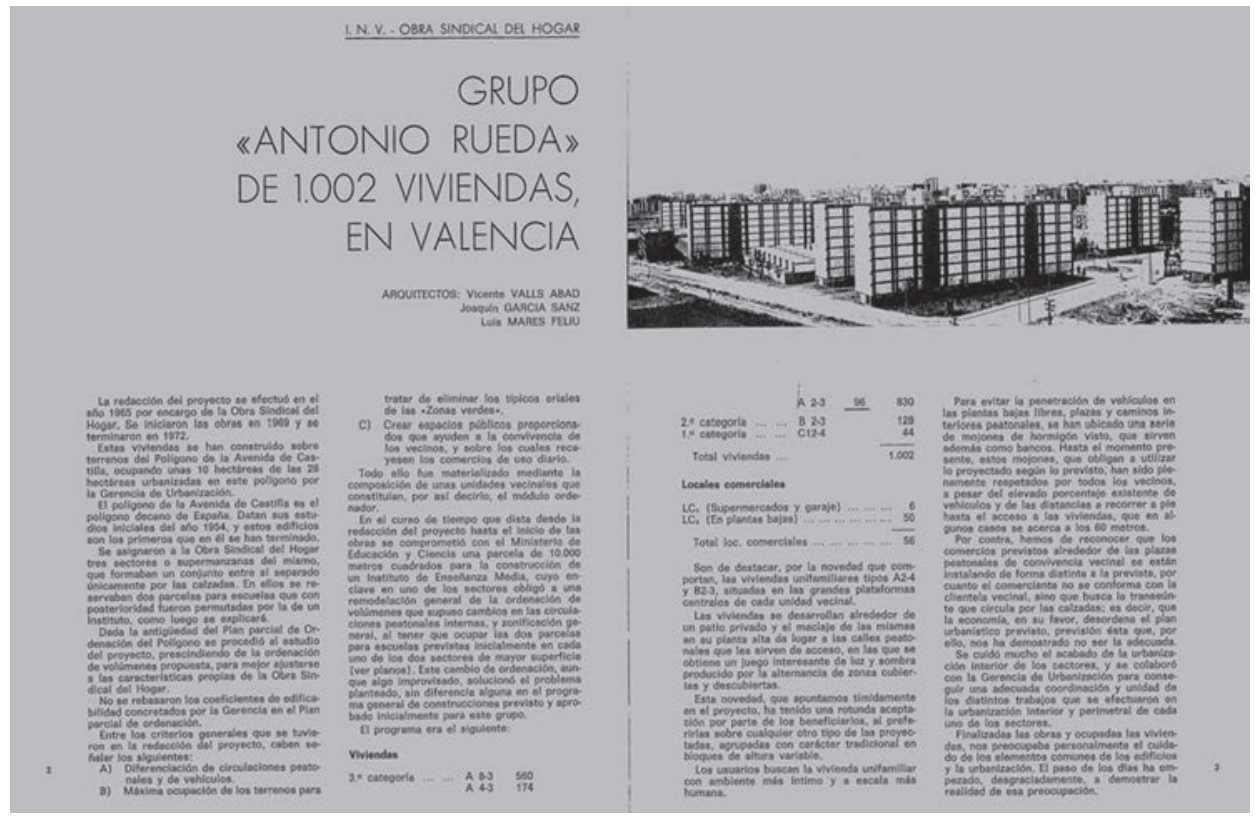

La OSH llevó a cabo sus propuestas por todo el territorio nacional, pero desarrollaría algunas de las más innovadoras en la ciudad de Madrid.

Para llevar a cabo los nuevos asentamientos de vivienda en el extrarradio de Madrid, Julián Laguna, Comisario de Urbanismo de Madrid, involucró a arquitectos que, entre otros, acabarían conformando la nueva modernidad del panorama nacional. El primero de los Polígonos, Entrevías (1956-1960) fue desarrollado por Manuel Sierra y Francisco Sáenz de Oiza, seguido por Canillas (1957-1958) de Luis Cubillo, Manoteras (1957-1958) de Manuel Ambrós, Mariano García de Benito, Eduardo García y Enrique Quereizaeta, Orcasitas (1956-1959) de Rafael Leoz y Joaquín Ruiz Hervas, Fuencarral (1958-1960) de José Luis Romany, Almendrales ( 1959-1973) por Francisco Javier Carvajal, José A. Corrales, José M. García Paredes y Ramón Vázquez Molezún. ${ }^{9}$

9 Fernández-Galiano, Luis; Justo F. Isasi, Justo; Antonio Lopera. La quimera moderna. Los Poblados dirigidos de Madrid en la arquitectura de los 50. Madrid: Hermann Blume, 1989
Figura 2.3. Artículo sobre el Grupo "Antonio Rueda" en Hogar y Arquitectura 54 (1973) 
Figura 2.4. 1956-1959, Poblado de Caño Roto, vista del conjunto. Fuente: Hogar y Arquitectura 54 (1964)
Figura 2.5. 1956-1959, Poblado Dirigido de Caño Roto, I ${ }^{a}$ Fase. Fuente: Hogar y Arquitectura 54 (1964)
Pero uno de los conjuntos que, en palabras de Vicente Valls ${ }^{10}$, sirvió de referencia al equipo valenciano en la proyectación del Grupo Antonio Rueda, fue la experiencia del Poblado Dirigido de Caño Roto situado en el Carabanchel Alto, al suroeste de Madrid y, en particular, la segunda de sus tres fases. (Fig.2.4)
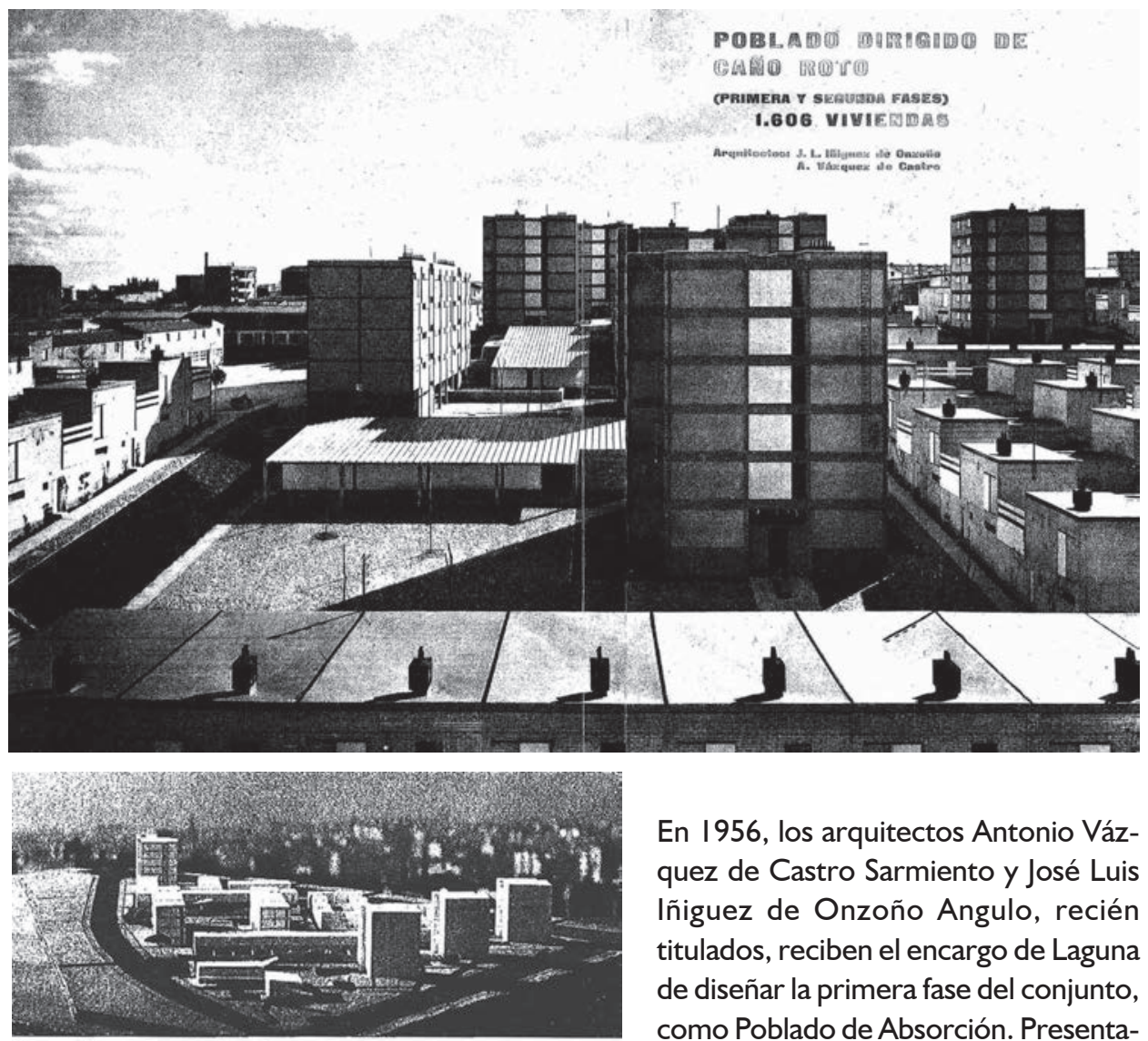

En 1956, los arquitectos Antonio Vázquez de Castro Sarmiento y José Luis Iñiguez de Onzoño Angulo, recién titulados, reciben el encargo de Laguna de diseñar la primera fase del conjunto, como Poblado de Absorción. Presenta-

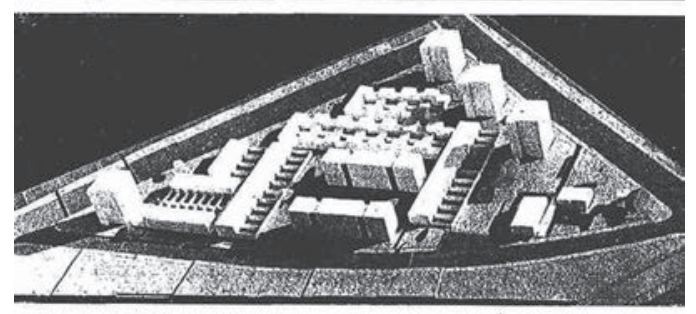
do el proyecto en 1957, en 1959 estaba concluido. (Fig. 2.5) La segunda fase, comenzaría poco después, conformó con la primera el Poblado de Caño Roto con un total de I. .600 viviendas.

En la segunda fase, el interés del conjunto radica en el uso conjugado de vivienda unifamiliar con patio y en viviendas agrupadas en bloque con 40 6 niveles, junto a equipamientos que dotaban al conjunto de autosuficiencia respecto a la ciudad. La experiencia adquirida en el primer proyecto propicia pequeños cambios, especialmente de tipo constructivo, que permitirían generar un conjunto con mejores resultados.

10 Valls exponía esta referencia con ocasión de la visita realizada al Grupo de Viviendas Antonio Rueda guiada por Vicente Valls Abad y el arquitecto técnico Jorge García Valdecabres, organizada por el CTAV, 2008 
El poblado se ordena a partir de la geometría y su adaptación al terreno a través de una trama ortogonal en base a una óptima orientación para el soleamiento y la ventilación y que ordena los diferentes volúmenes de viviendas, las calles y las zonas verdes y arboladas. Los edificios en altura se desarrollaron de dos tipos siendo el bloque lineal su planteamiento más vanguardista. Se retoman los ideales del CIAM, con estructura de hormigón, corredores abiertos por galerías cada dos niveles y viviendas mínimas desarrolladas en dúplex. Éstos quedan envueltos de zonas ajardinadas $y$, a su vez, se posicionan rodeando las agrupaciones de unifamiliares que se compactan volcando a patios de uso privado como áreas de expansión de la vivienda. Las unifamiliares se resuelven con una mayor variedad de tipos, en relación a diversos modos de agrupación y de adaptación a la topografía e incorporan elementos vernáculos como el patio o el callejón, que dotan de un carácter más popular al conjunto. (Fig. 2.6)

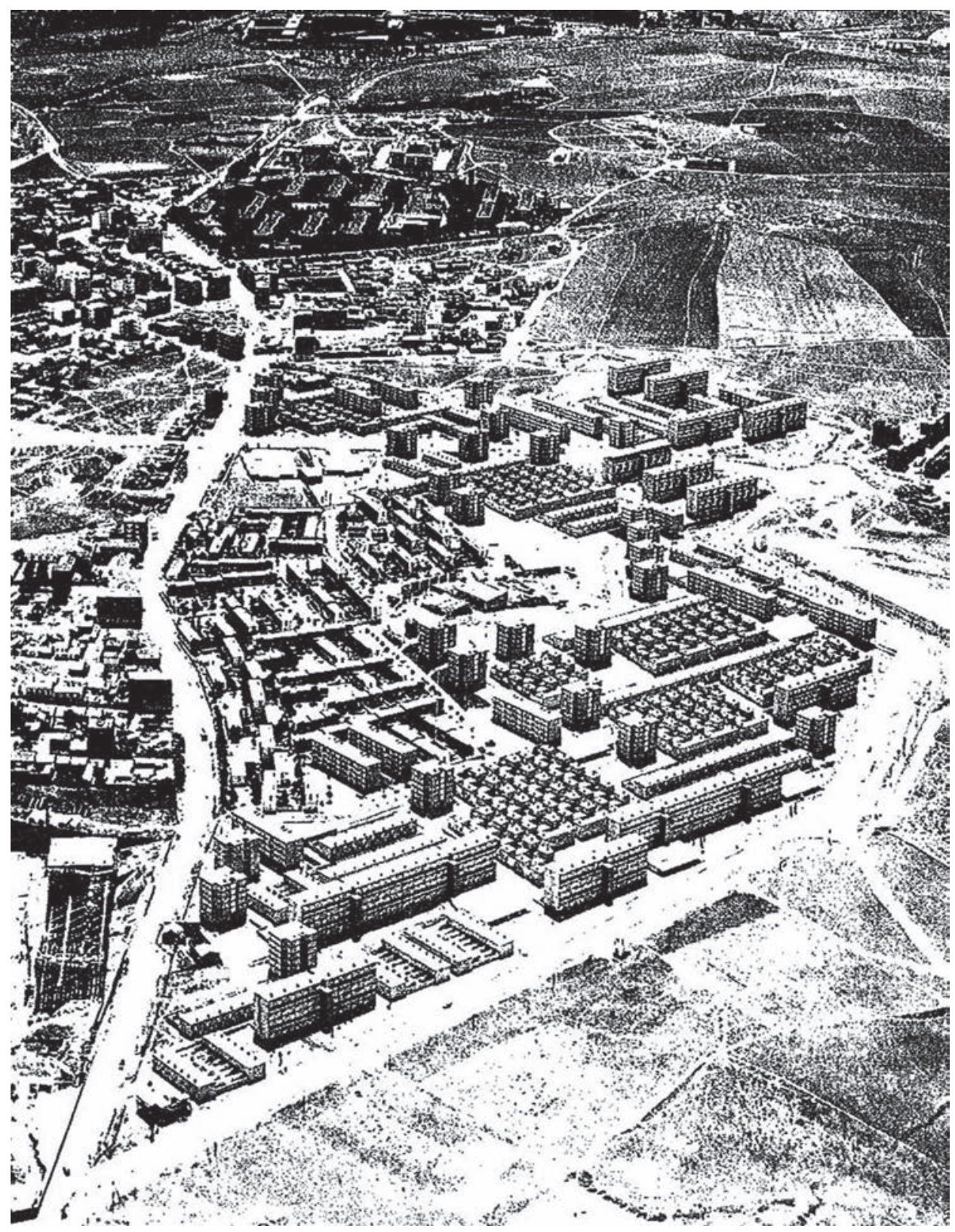

El centro cívico se situó en el centro de gravedad de las dos primeras fases y se desarrolló en dos niveles aprovechando la topografía del terreno. En el nivel superior se situaba la plaza, el centro parroquial, la sala de espectáculos y los comercios. En el nivel inferior un
Figura 2.6., 1956-1959, Poblado de Caño Roto, vista aérea, 1960. Fuente: Hogar y Arquitectura 54 (1964) 
Figura 2.7. 1956-1959, Poblado de Caño Roto, plano de ordenación general. Fuente: Hogar y Arquitectura 54 (1964)
Figura 2.8. 1956-1959, Poblado de Caño Roto, $3^{a}$ Fase. Fuente: Hogar y Arquitectura 54 (1964) centro comercial y un supermercado. Por el resto del poblado, se dispersaron espacios para artesanías, garajes y comercios complementarios. Las escuelas se dispusieron en espacios acotados en las zonas verdes circundantes. (Fig. 2.7)

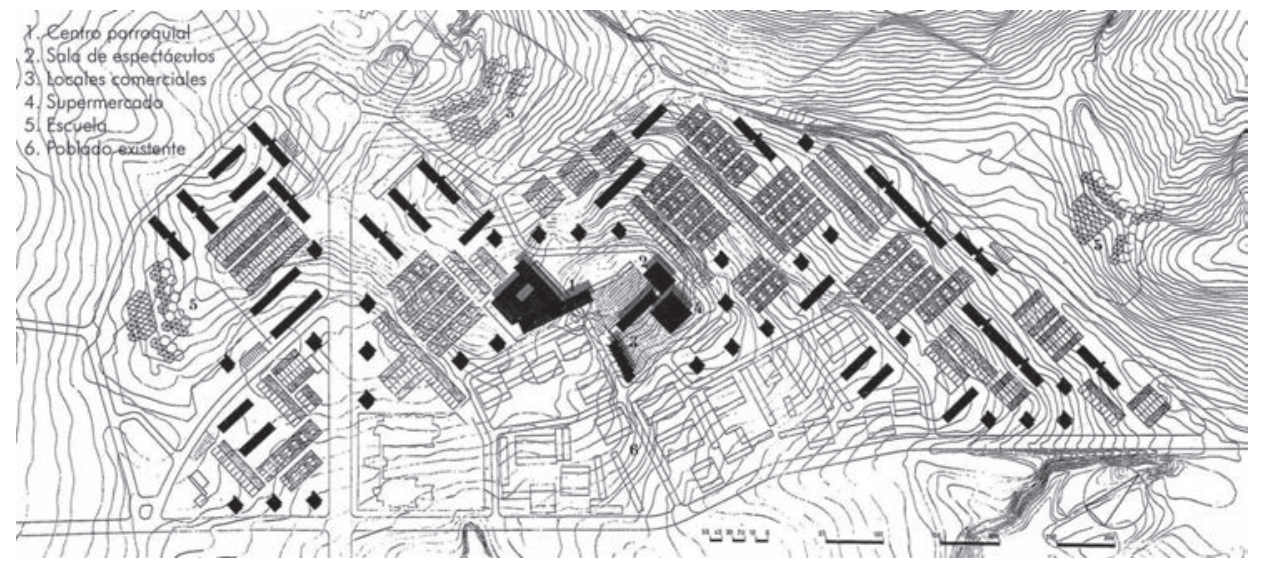

La tercera fase ${ }^{\prime \prime}$, realizada hacia 1964, nace del planteamiento de articular y conciliar la ordenación geométrica ortogonal del poblado en su segunda fase y la ordenación primigenia circundante conformada por manzanas cerradas. Se recurrió a la utilización de un bloque tipo en forma hexagonal, con núcleo de comunicaciones vertical en su eje central desde el que se accede a cada vivienda situada a un nivel diferente. El sistema permitía, además, entrelazar cada torre con el contiguo por uno de sus lados. Las viviendas, establecidas en tres categorías en relación a la superficie, se disponen a diferentes niveles enfatizando este hecho en su fachada. Su correcta iluminación y ventilación queda garantizada al proporcionar a cada vivienda tres de sus fachadas libres. La vinculación con el conjunto del poblado quedaba garantizada por su materialidad basada en la utilización del hormigón visto en la estructura y ladrillo cerámico macizo cara vista en los paños de cerramiento que conjugaban con la apertura de huecos horizontales. (Fig. 2.8)
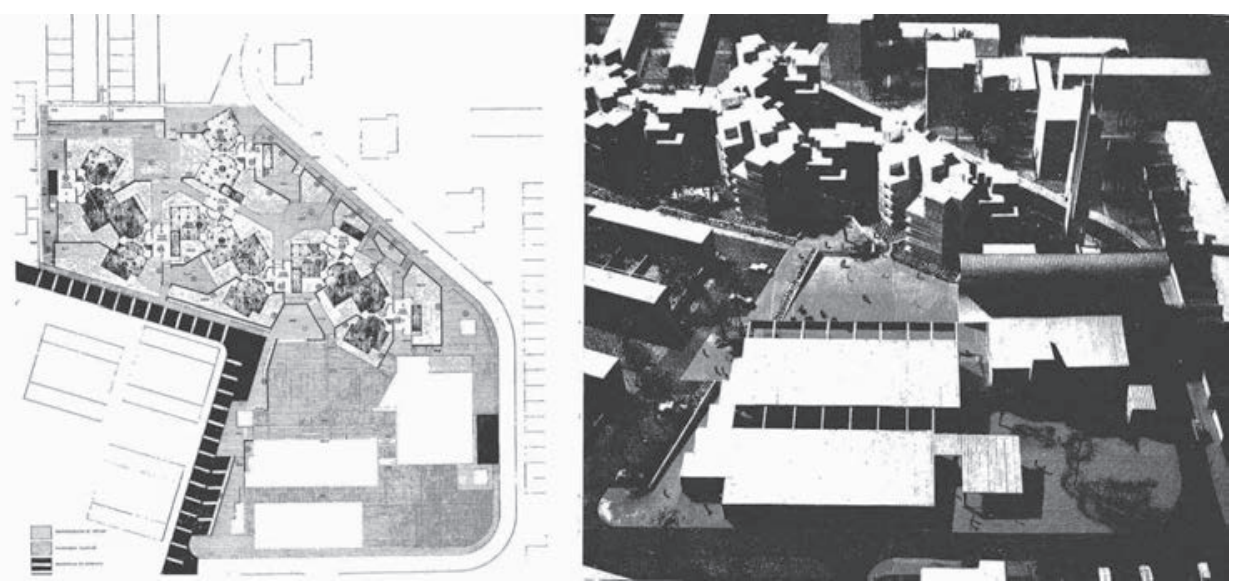

Al referirse al Poblado en 1964 y, en particular a su segunda fase, el arquitecto Carlos Flores, apuntaría: "se caracteriza antes que nada por esta solidez de la idea madre, por su equilibrio, su coherencia y su realismo(...) de un planteamiento lógico y extraordinariamente maduro", "se reconoce como una de las pocas obras realmente importantes que ha producido la arquitectura española en los últimos lustros. Y, sin embargo, aquí está la paradoja: Caño Roto ha sido escasísimamente imitado, asimilado o seguido." y prosiguió “Caño Roto es un barrio esencialmente humano donde la gente puede encontrarse a gusto dentro y fuera de las viviendas." 12

II Poblado de Caño Roto ( $3^{\text {a }}$ fase) Madrid, en Hogar y Arquitectura, No. 54, 1964; pp. 2-7

12 Carlos Flores "El poblado de Caño Roto" en Hogar y Arquitectura No. 54, Madrid ( 1964), pp. 35-38 
En efecto "Caño Roto" adquirió reconocimiento por la sensatez de la propuesta y fue publicado no sólo en las revistas especializadas nacionales sino en revistas internacionales como L'Architecture d'Aujord'hui en 1959, Werk en 1962, Zodiac en 1964, Aujourd'hui Art + Architecture en 1965 y la alemana revista Baumeister en 1967. De algún modo el Grupo "Antonio Rueda" de Valencia, al ser concluido en 1972, reconoce esa inspiración y le rinde su particular homenaje.

\section{EL GRUPO DE VIVIENDAS DE RENTA LIMITADA “ANTONIO RUEDA"}

Con independencia de la influencia de "Caño Roto", Valls ya había adquirido una experiencia propia en la construcción de viviendas sociales desde que en 1957 fuese nombrado arquitecto de la OSH. Bajo esta circunstancia y rodeándose de diferentes equipos de arquitectos llevaría a cabo diversos grupos de vivienda social en el ámbito levantino.

Una de las primeras experiencias de la OSH en la ciudad de Valencia, fue el Grupo Virgen del Carmen, diseñado por Fernando Martínez García-Ordoñez y Juan María Dexeus Beatty $^{13}$, y en cuya dirección de obra participaron los arquitectos Vicente Valls Abad en representación de la OSH y Mauro Lleó Serret en representación de la Delegación Provincial del Instituto Nacional de la Vivienda. El grupo, situado en un extremo de los poblados marítimos, fue la única intervención realizada del "Plan Riada"|4 que suponía la construcción de 1.000 viviendas encargada a la OSH para la ciudad de Valencia. Si bien se desarrolló bajo un mismo proyecto, de las 6I4 viviendas del conjunto completo, la OSH resolvió 232 de ellas en la zona norte del solar. (Fig. 3.I)
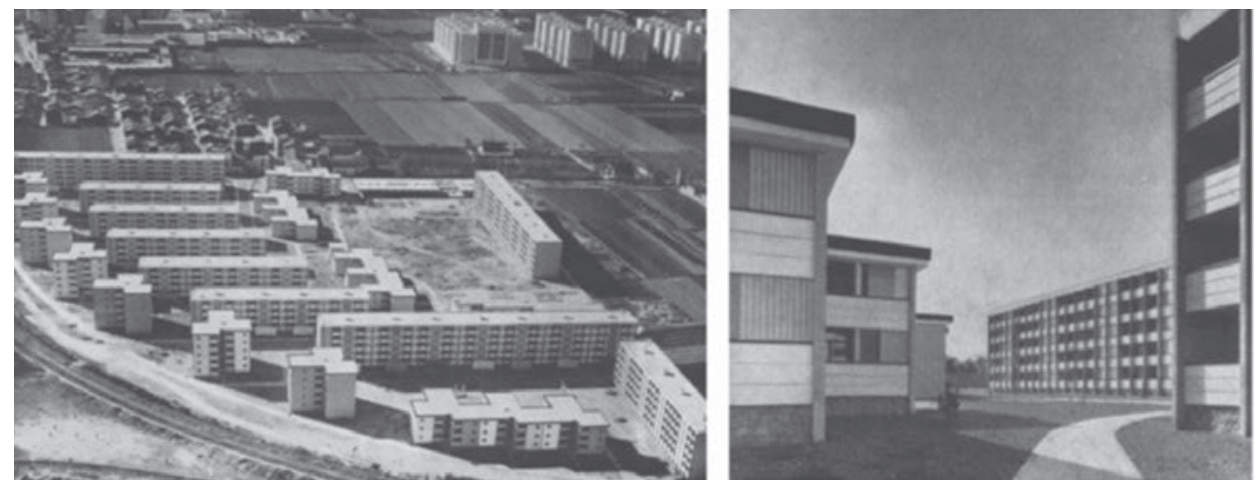

De un modo modesto el conjunto contempló en su ordenación aspectos como la separación de tráficos, la definición de espacios verdes y la inserción de mínimos equipamientos como una escuela, la cual no se ejecutaría hasta unos años más tarde. Se utilizaron dos tipos de bloques, lineales de 4 y 5 plantas con 2 viviendas por planta y torres en forma de T de 3 a 5 plantas, con 3 viviendas por nivel. Todas las viviendas contaban con ventilación cruzada y una búsqueda de orientación óptima combinada con la utilización de materiales estandarizados. De este modo se cumplía con los requisitos antes mencionados buscados por la OSH: mínimas dimensiones, mínimos estándares y mínimos costes.

13 Tras esta experiencia conformarían el equipo GO-DB Arquitectos. Para más información consultar la Tesis doctoral: Palomares Figueras, M. Teresa. La producción experimental de GO.DB Arquitectos. (Directora: Carmen Jordá Such) Valencia: UPV, 20 I0. [Biblioteca de la Universidad Politécnica de Valencia-UPV].

I4 El I3 y I4 de Octubre 1957, la ciudad de Valencia sufrió la doble Riada del rio Turia, que inundó gran parte de la ciudad y dejó a una gran parte de la población sin viviendas y sin otros equipamientos como las escuelas. Para resolver el problema se aprobó un plan de emergencia, "El Plan Riada", que además de las ayudas estatales contó con aportaciones económicas extranjeras. No obstante la consecución del Plan no se completó como estaba previsto.
Figura 3.I. 1958-1962, Grupo Virgen del Carmen, imagen aérea y vista general 
Figura 3.2. 1960-1962, Polígono de Vistabella. imagen aérea y vista general

Figura 3.3. 1965-1970, Grupo Antonio Rueda, imagen aérea y vista general
En 1960, Valls intervendrá junto a Víctor Bernal y Roberto Soler en el Grupo "La Paz" del Polígono de Vistabella de I.I48 viviendas en Murcia. Un conjunto que combina en su ordenación una mayor variable de tipologías y alturas, consiguió un orden interno para un barrio autosuficiente en la zona este de la ciudad. (Fig. 3.2)
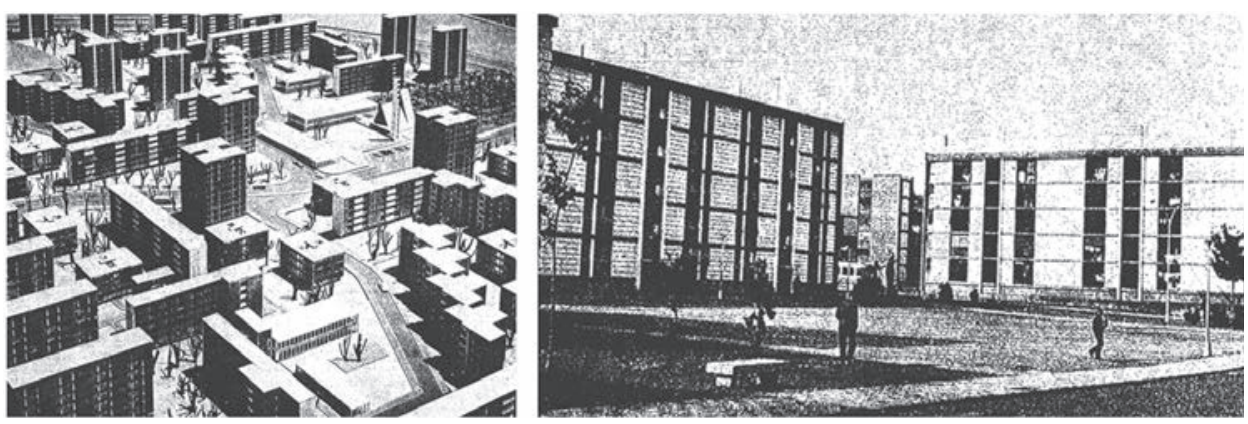

Tras la experiencia adquirida y con la influencia ya comentada de Caño Roto, Vicente Valls, junto a los arquitectos Joaquín García Sanz y Luis Marés Feliu reciben el encargo en 1965 de la OSH para la realización de 1.000 viviendas y que se formalizaría en el Grupo “Antonio Rueda" de viviendas de renta limitada. (Fig. 3.3)Posteriormente Valls y García Sanz, junto a Francisco Mensúa realizarían el Grupo "Vicente Mortés" en el Polígono de la Fuente de San Luis, fueron éstas las dos últimas realizaciones de la OSH en la ciudad de Valencia.
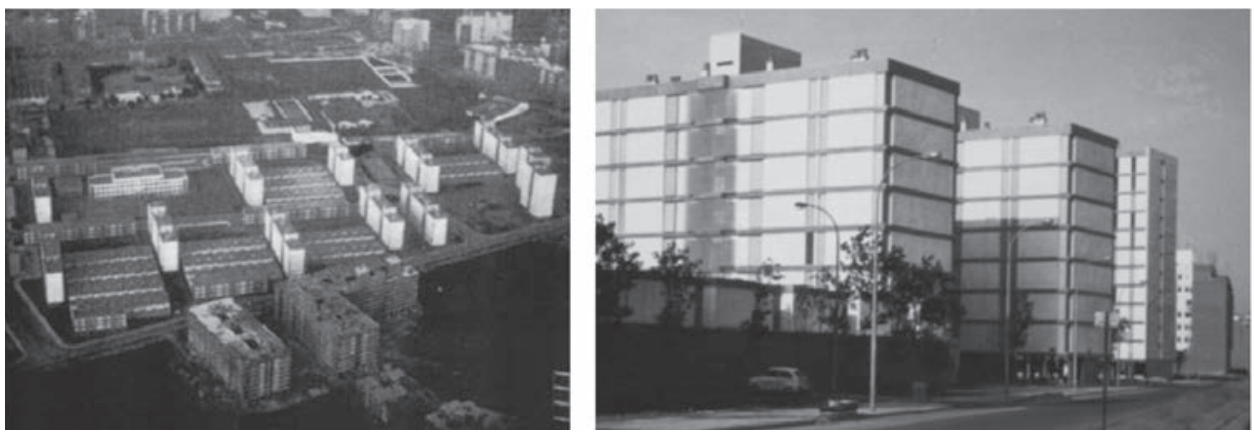

\section{El encargo}

En 1960 el Ayuntamiento de Valencia solicita al Ministerio de la Vivienda las ayudas extranjeras recibidas para solventar el problema de la vivienda tras la riada del 57 que había sufrido la ciudad. La concesión es realizada con la condición que éstas se realicen bajo el amparo de la OSH y con ejemplo del ya construido Grupo "Virgen del Carmen”. (Fig. 3.4)

Se propuso para su ejecución el área del Polígono de la Avenida de Castilla en la zona suroeste de la ciudad, con una superficie de 28 hectáreas, 10 de las cuales fueron las adjudicadas a la OSH subdivididas en tres manzanas y límite al sur por las vías del tren a Castilla.

Desde 1954 ya existía un Plan de Ordenación de la Zona, a partir de la construcción de manzanas cerradas, típicas de los ensanches del XIX. Por ello, se realizó un estudio que permitiese trabajar con edificación abierta para que cumpliese por un lado las expectativas de la OSH así como las aspiraciones de los arquitectos y todo ello sin rebasar los coeficientes de edificabilidad concretados por la Gerencia en el Plan Parcial de Ordenación. 


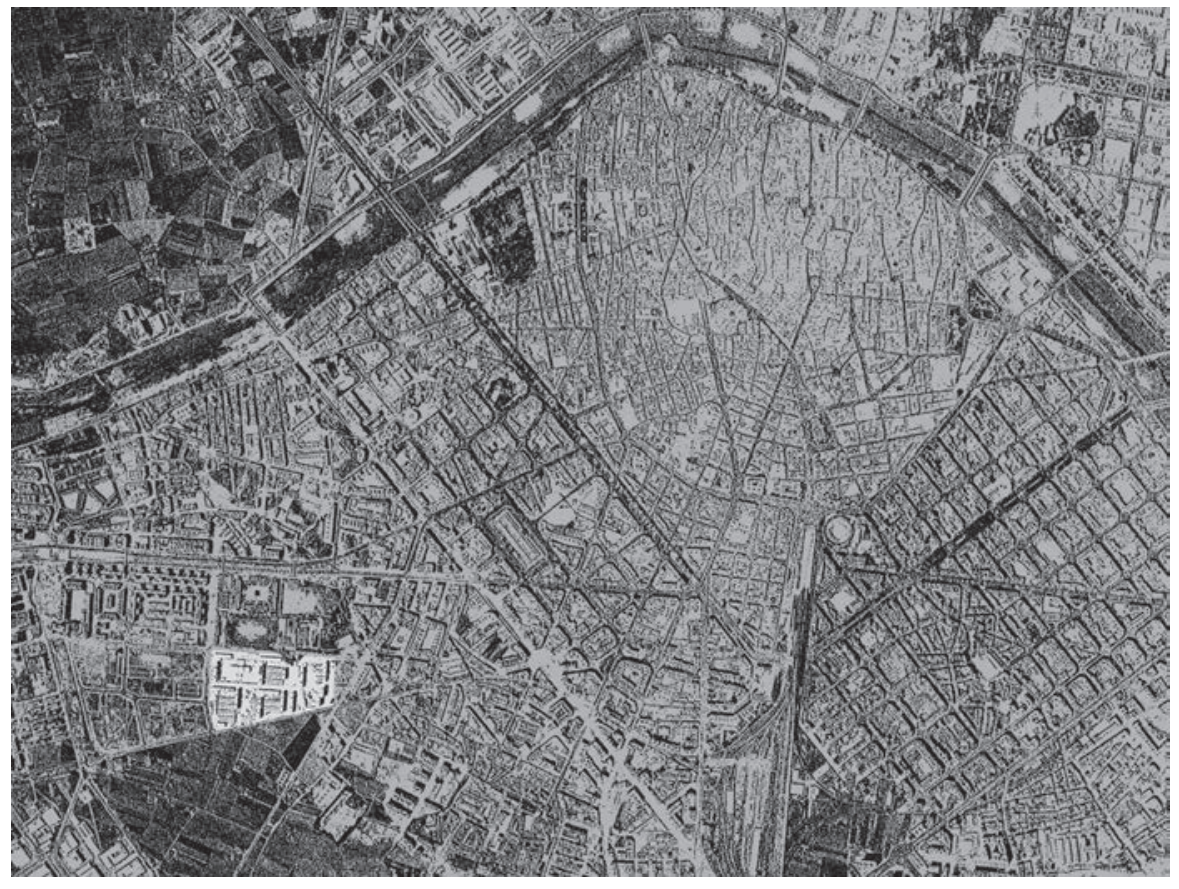

Entre los criterios esenciales para la redacción del proyecto primaron aspectos como:

“a) Diferenciación de circulaciones peatonales y de vehículos.

b) Máxima ocupación de los terrenos para tratar de eliminar los típicos eriales de las "zonas verdes".

c) Crear espacios públicos proporcionados que ayuden a la convivencia de los vecinos, y sobre los cuales recayesen los comercios de uso diario." ${ }^{5}$ (Fig. 3.5)

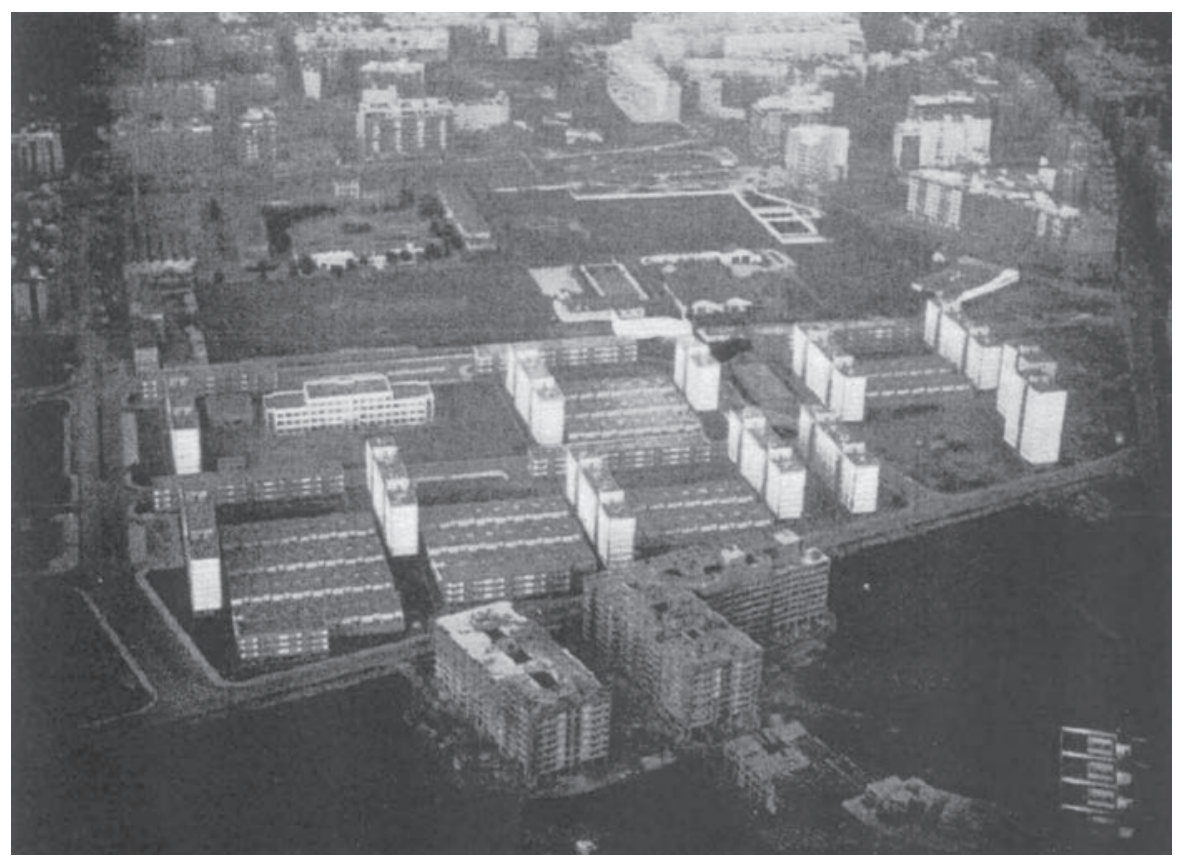

15 "Grupo "Antonio Rueda" de 1.002 viviendas en Valencia" en Hogar y Arquitectura, No. 106, mayo-junio I 973. p. 2
Figura 3.4. Imagen Aérea Valencia, 1972. Fuente: Hogar y Arquitectura 100 (1972)
Figura 3.5. 1965-1970, Grupo Antonio Rueda. Vista aérea, 1974 


\section{La ordenación del conjunto: la unidad vecinal y los equipamientos}

Las anteriores premisas se materializaron en un conjunto cuya composición se efectúa a partir del diseño de la Unidad Vecinal y su disposición repartida por los tres sectores que conforman el solar, cada uno de ellos separados por viales menores.

En la maqueta, realizada para presentar la propuesta, esta unidad se repetía hasta siete veces adaptándose a la geometría de cada sector. (Fig. 3.6) Sin embargo, debido al paso de casi cuatro años desde la redacción del proyecto hasta la ejecución, la OSH adquirió un compromiso con el Ministerio de Educación y Ciencia para la construcción de un edificio de Enseñanza Media con una superficie de $10.000 \mathrm{~m}^{2}$. Lo que obligó a realizar cambios en la volumetría general y en los recorridos internos, pero que no desvirtuaron el programa inicial. Se decidió ubicarlo en el sector más norte y debido a la dimensión obligó a eliminar de una de las unidades vecinales, la agrupación de viviendas unifamiliares y uno de los bloques de 8 niveles. Se mantuvieron así los dos bloques de 8 y 4 alturas respectivamente que cerraban el conjunto respecto a los viales recayentes. Los otros dos sectores se mantuvieron fieles a la propuesta inicial. (Fig. 3.7)

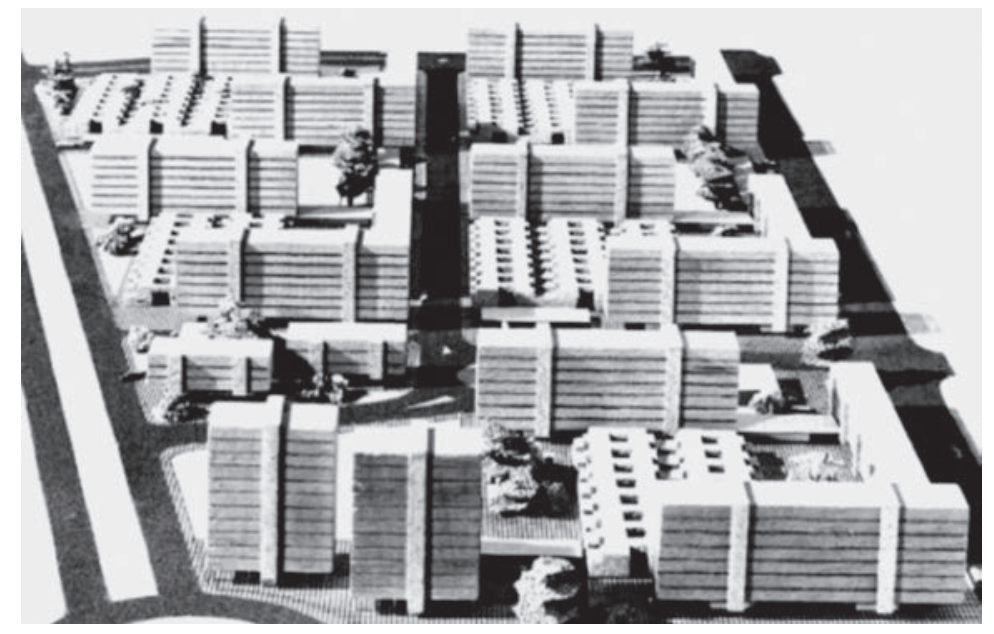

Figura 3.6. 1965-1970, Grupo Antonio Rueda. Maqueta de la propuesta inicial, 1965

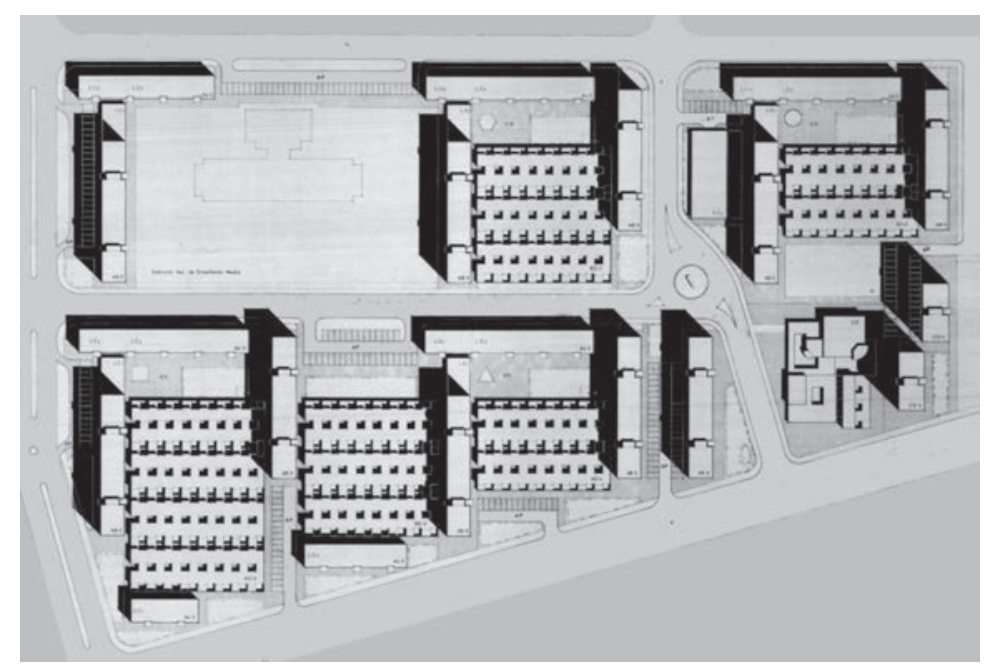

Los equipamientos, aparecen como parte integrante del conjunto para dotarlo de la necesaria autosuficiencia, y pese a que no llegaron a materializarse completamente, fundamentalmente por motivos económicos y de gestión, cabe hacer hincapié en la disposición original de estos dentro de la ordenación del conjunto. 
El sector situado al este, el de menor dimensión, queda organizado por una unidad vecinal y dos torres. Se plantea en él la ubicación de un Centro Parroquial, un local comercial en un volumen independiente de un solo nivel y se reserva una parcela en el centro de gravedad del sector para construir una Guardería Infantil. Alrededor se plantean áreas arboladas dando prioridad a una secuencia de recorridos peatonales que permitiesen recorrer el sector, a la vez que vincularse con los otros dos. (Fig. 3.8)

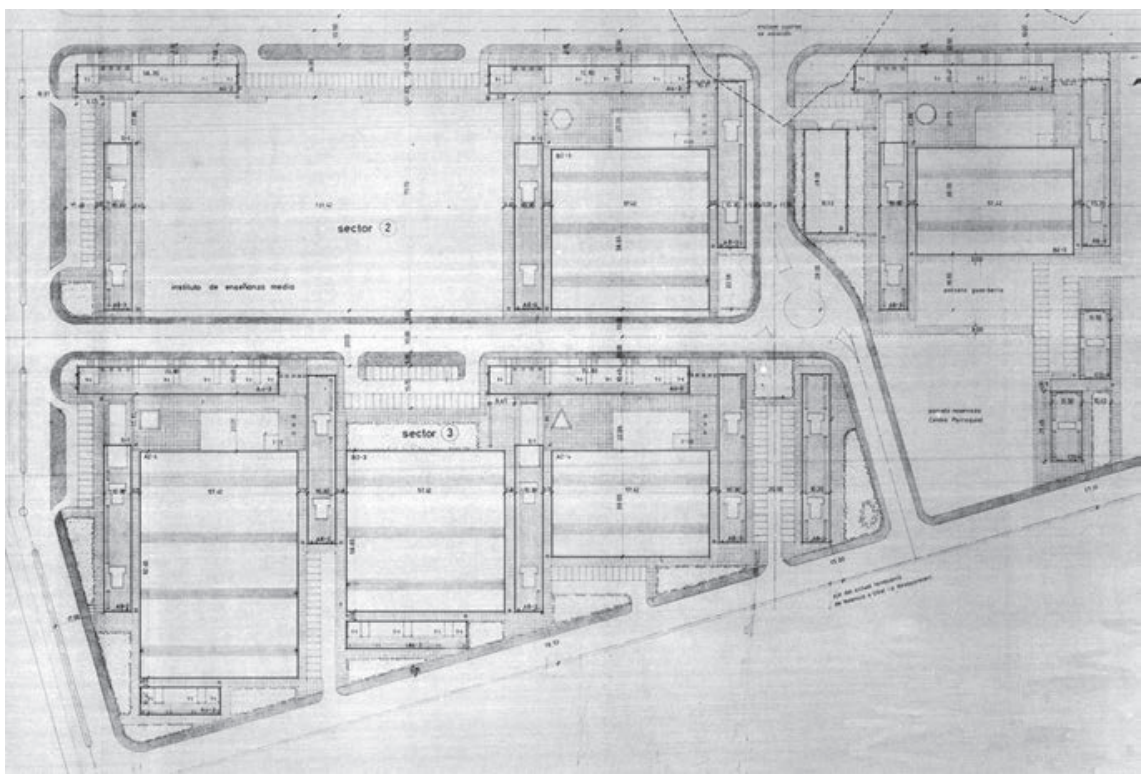

El sector más al norte, se ejecuta con una unidad vecinal completa y parte de otra, tras eliminar las viviendas unifamiliares y uno de los bloques de 8 niveles para ubicar en él el Instituto de Enseñanza Media requerido.

El tercer sector que se extiende al sur de la parcela dispone tres unidades vecinales con sutiles modificaciones que permiten adaptarse al trazado oblicuo del vial principal, siendo las agrupaciones de viviendas unifamiliares de cada unidad las que crecen o disminuyen para adaptarse con su trama ortogonal a la irregularidad del sector.

La mezcla de bloques lineales, torres y agrupaciones de viviendas unifamiliares, obtienen aquí un resultado muy positivo. El conjunto urbano acaba con una ordenación a partir de una unidad que se agrupa dentro del conjunto, y que contiene el "módulo vecinal”, de unas 200 viviendas. Esta forma de agrupar genera una impecable ordenación que, además, viene reforzada por el uso sistemático del módulo de $2.90 \times 2.90 \mathrm{~m}$. que se manifiesta tanto en la estructura como en las distribuciones y elementos constructivos. (Fig. 3.9)

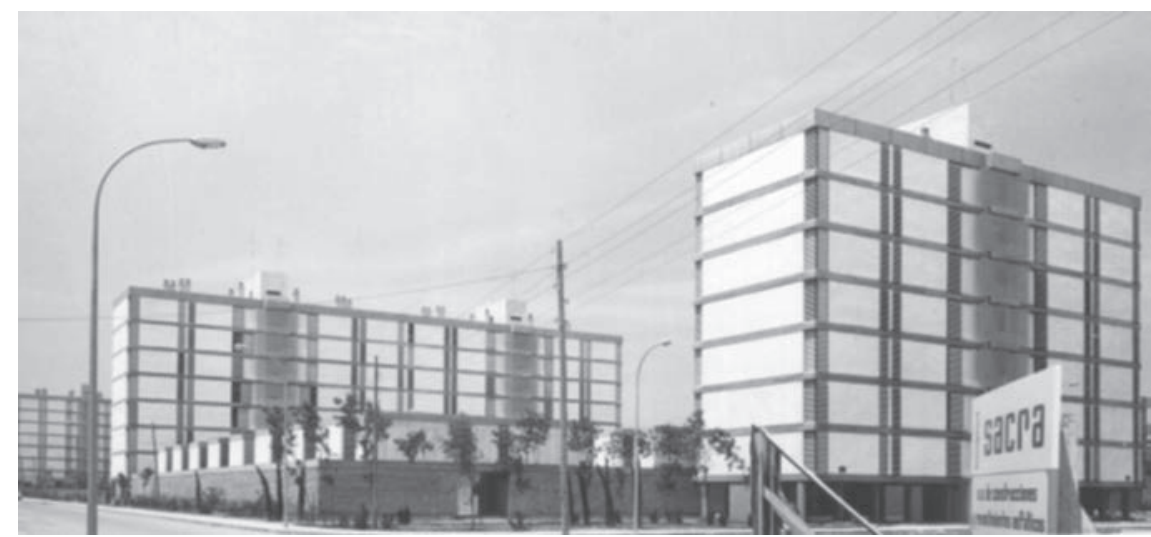

Figura 3.8. 1965-1970, Grupo Antonio Rueda. Planta baja del conjunto
Figura 3.9. 1965-1970, Grupo Antonio Rueda. Imagen de época. Fuente: Hogar y Arquitectura 106 (1973) 
Figura 3.10. 1965-1970, Grupo Antonio Rueda. La Unidad Vecinal, planta de cubiertas
Cada módulo vecinal, que conforma el conjunto, adquiere la suficiente flexibilidad para adaptarse a las irregularidades geométricas de cada parcela y el juego de ordenación de volúmenes queda remarcado por el vaciado estratégico para zonas ajardinadas, equipamientos y áreas de aparcamiento.

La Unidad Vecinal contiene dos bloques lineales de ocho plantas, con orientación este-oeste y viviendas a una orientación, un bloque lineal de cuatro plantas con orientación norte-sur y viviendas pasantes, y un conjunto compacto de viviendas unifamiliares de dos niveles, la "casbah cartesiana" en palabras de sus autores, conformadas con unidades de dos, tres o cuatro calles cubiertas pero cuidadosamente pautadas por la iluminación creada por la alternancia de patios. (Fig. 3.10 y Fig. 3.1I)
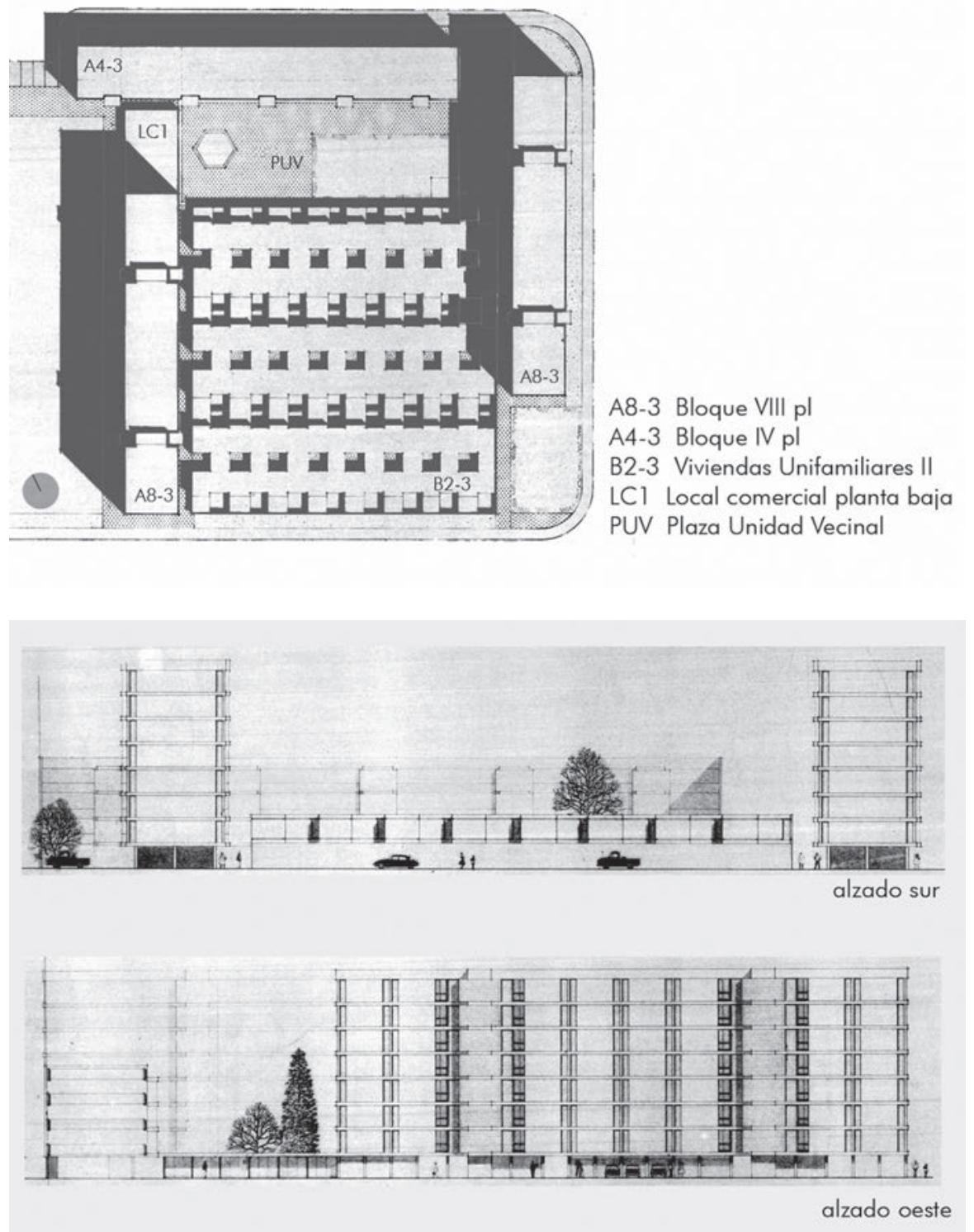

Las áreas de recreo se resuelven a modo de pequeñas plazas de escala controlada como se requería desde las premisas del proyecto y, por lo tanto, quedan vinculadas a cada unidad vecinal. La dimensión de las mismas es acorde a la población de cada unidad, y de este modo el mantenimiento de las áreas verdes queda garantizado por los propios vecinos. (Fig. 3. I2) 


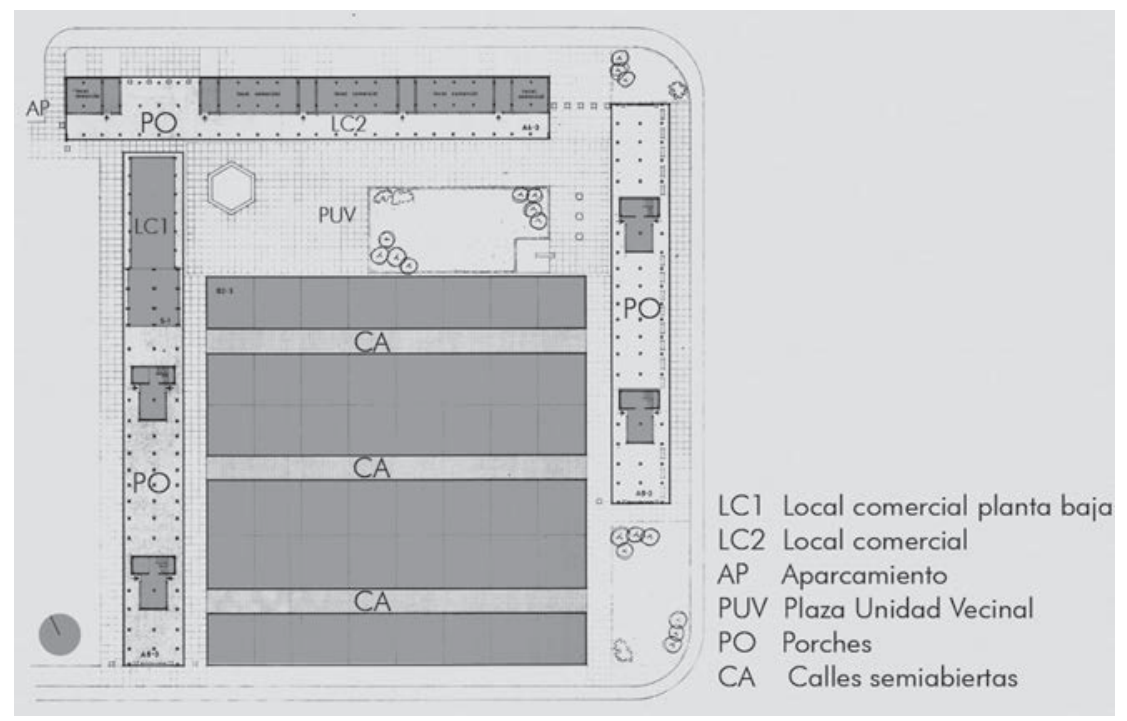

Con la misma lógica se ubican los locales comerciales dispersándolos por toda la ordenación. Unos ocupan la planta baja de los bloques de menor altura, los orientados en dirección norte a sur. Los comerciales recaen no sólo a la plaza vecinal sino también a las calles colindantes $y$, por lo tanto, son fácilmente reconocibles, accesibles y utilizables por la población circundante, integran la vida del conjunto a la de la ciudad. Pero también aparecen otros, ligados a los bloques de 8 niveles, en dirección este-oeste que, a modo de extensión, resuelven el cierre de la plaza vecinal al oeste a la vez que buscan la relación con la unidad adyacente. (Fig. 3.13)

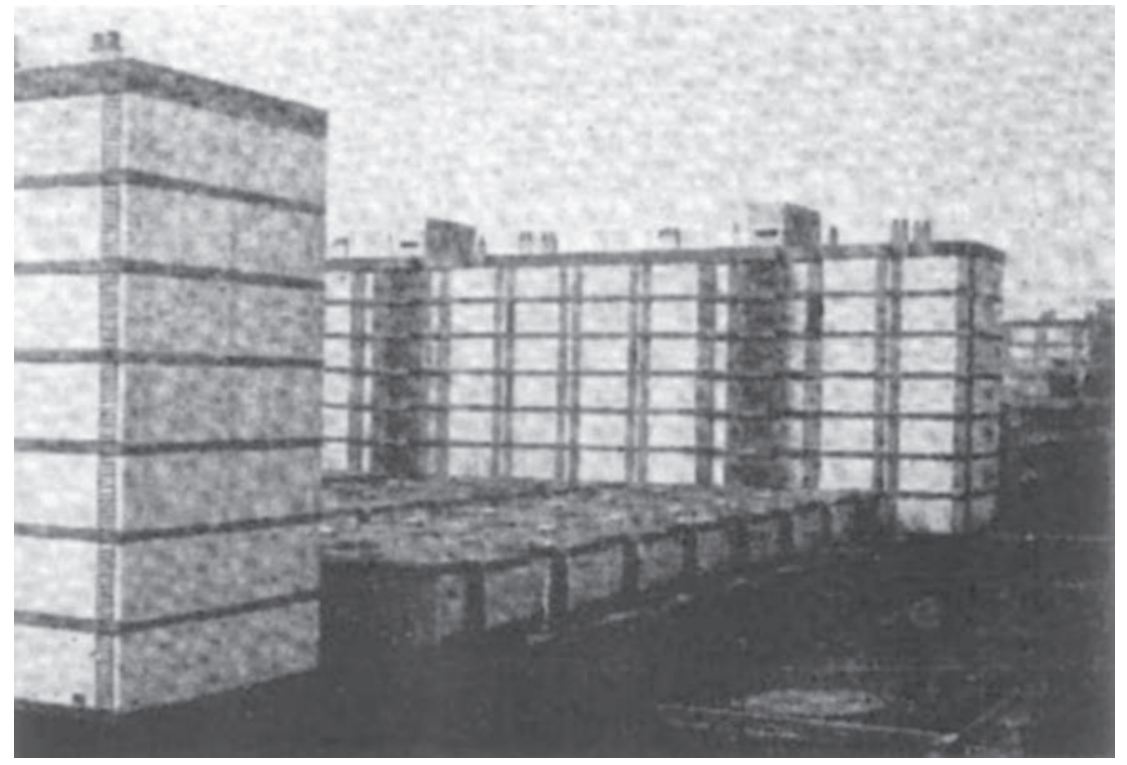

Para conseguir coser la unidad del conjunto, en su sentido este-oeste, se liberan las plantas bajas de los bloques lineales de ocho alturas, lo que proporciona áreas colectivas porticadas a la vez que se obtiene un recorrido visual del conjunto.

Las zonas de aparcamiento, quedaron situadas en las áreas externas de cada sector y en penetraciones realizadas por viales en forma de "cul de sac". Es relevante la incorporación de unos bancos que cuidadosamente dispuestos, al acotar el espacio de porches, han evitado que acabasen siendo utilizados como aparcamientos improvisados por sus vecinos tras el aumento del parque automovilístico experimentado desde su construcción.
Figura 3.12. 1965-1970, Grupo Antonio Rueda. La Unidad Vecinal, planta baja

Figura 3.13. 1965-1970, Grupo Antonio Rueda. Imagen de época. Fuente: Hogar y Arquitectura 106 (1973) 
El conjunto, gracias a la alternancia de tipologías edificatorias, adquiere variedad volumétrica dentro de un orden establecido reconocible a través de la sistematización del uso de la Unidad Vecinal y junto a los recursos utilizados como las calles parcialmente cubiertas de las viviendas unifamiliares y los porches bajo los edificios orientados este-oeste, constituyen los aspectos urbanísticos más interesantes alcanzados en el grupo.

\section{Los bloques tipo: tipologías y materialidad}

Las tipologías de viviendas se resuelven en función de tres categorías, según la normativa de la propia OSH y pretenden aunar bajo un mismo barrio diferentes tipologías adaptables a las diferentes clases sociales. Indudablemente ha ocasionado un barrio diverso $y$, por lo tanto, más ajustado a la realidad de lo que debe ser la ciudad, carente de guetos excluidos por su pertenencia a una determinada clase social. (Fig. 3.14)

\begin{tabular}{|c|c|c|c|c|c|c|c|c|c|c|}
\hline \multicolumn{11}{|c|}{ CUADRO DE TIPOLOGIAS } \\
\hline \multicolumn{9}{|c|}{ VIVIENDAS } & \multicolumn{2}{|l|}{ EQUIPAMIENTOS } \\
\hline categoria & tipo & $\begin{array}{l}\pi^{\circ} \\
\text { dormitorios }\end{array}$ & $\mathrm{m}^{2}$ & $\begin{array}{l}n^{0} \text { viviendas } \\
\text { por bloque }\end{array}$ & $\begin{array}{l}n^{\circ} \\
\text { unidades }\end{array}$ & $\begin{array}{l}\mathrm{n}^{\circ} \\
\text { viviendas }\end{array}$ & $\begin{array}{l}n^{\circ} \\
\text { plantas }\end{array}$ & $\begin{array}{l}\text { tipologia } \\
\text { edficatoria }\end{array}$ & \multicolumn{2}{|l|}{ tipologia } \\
\hline $1^{*}$ & C $12-4$ & 4 & 140.14 & $(11 p \mid x 2 v) 22$ & 2 torres & 44 & $P B+X \mid$ & torre & Centro Parroquial & Pr, noct \\
\hline $2^{*}$ & B2.3 & 3 & 88.80 & $16 \mathrm{v}$ por cale & 8 cales & 128 & ॥ & $\begin{array}{l}\text { Untamiliar } \\
\text { adosada }\end{array}$ & $\begin{array}{l}\text { Instituto Nacional } \\
\text { Ensefianza Media } \\
\end{array}$ & Pr, ct \\
\hline $3^{\circ}$ & A 8.3 & 3 & 76.00 & $(7 p b \times 4 v \times 2 u) 56$ & $\begin{array}{l}10 \\
\text { bloques }\end{array}$ & 560 & $P B+V I I$ & bloque ineal & Guarderia Intantil & $\mathrm{Pr}$, noct \\
\hline $3^{\circ}$ & A 43 & 3 & 75.97 & $\begin{array}{l}(3 p b 2 v \times 5 u) 30 \\
(3 p b 2 v \times 4 u) 24 \\
(3 p b \times 2 v \times 3 u) 18 \\
(3 p b \times 2 v \times 2 u) 12\end{array}$ & $\begin{array}{l}4 \\
1 \\
1 \\
1 \\
\text { bloques }\end{array}$ & 174 & PB+1II & bloque lineal & $\begin{array}{l}\text { LC1, en vol } \\
\text { independiente }\end{array}$ & 6 \\
\hline \multirow[t]{3}{*}{$3^{a}$} & B2-4 & 4 & 90.80 & 16v por cale & 6 cales & 96 & " & $\begin{array}{l}\text { Unifamiliar } \\
\text { adosada }\end{array}$ & LC2, en pl baja & 50 \\
\hline & & & & & & $1.002 \mathrm{v}$ & & & Aparcamiento & $\begin{array}{l}\text { En } \\
\text { superficie }\end{array}$ \\
\hline & & & & & & & & & $\begin{array}{l}\text { Areas verdes y } \\
\text { zona de juegos }\end{array}$ & Arboladas \\
\hline
\end{tabular}

La tipología más recurrente, correspondiente a una $3^{\mathrm{a}}$ categoría, es la que se desarrolla en el bloque lineal de ocho niveles, conformado por dos núcleos de escaleras y dispuesto en orientación este-oeste. Las viviendas siguen la tipología A8-3, con una superficie de 76 $\mathrm{m}^{2}$, resuelven un programa de cocina, salón-comedor y tres dormitorios en la que cada dependencia obtiene una misma orientación, este u oeste, según el lado en el que esté situado pues la planta de distribución se realiza simétrica respecto a sus dos ejes. Se obtienen cuatro viviendas por planta con un solo núcleo de comunicación vertical que incluye la escalera y dos ascensores y optimizan la superficie destinada a espacios comunes. Los baños se resuelven al interior, agrupando los de las viviendas colindantes con lo que se consigue la compactación del sistema de montantes y bajantes. (Fig. 3.15 y Fig. 3.16)
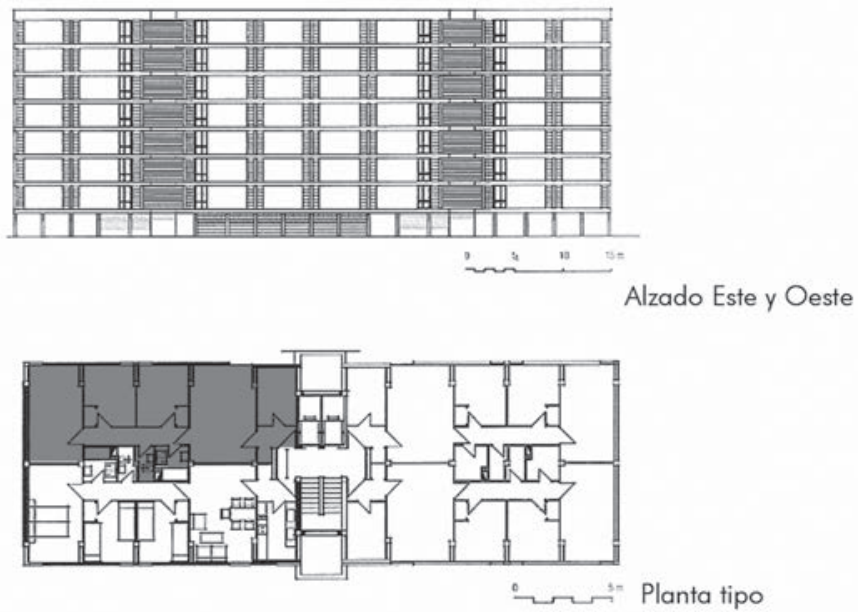
Las fachadas se entienden como un plano continuo, pautado horizontalmente por los cantos de forjado visto pintados en color gris, y el cambio de color entre éstos y los paños ciegos en los que se insertan los huecos de ventana de estrecha proporción y que reconocen la altura entre forjados tras un sistema de lamas fijas de tipo abatible de eje horizontal. Los núcleos de escaleras remarcan la verticalidad con la utilización de lamas horizontales que sobresalen del plano de fachada, ocultan tras de sí los tendederos de las galerías coincidentes con los núcleos verticales. La fachada pierde el tratamiento de plano único, y parece doblarse al conformar la esquina, con el hábil giro del hueco del dormitorio principal al final del bloque. La planta baja del bloque queda liberada, con excepción de los correspondientes núcleos de accesos, quedan pautada por la estructurada retirada del plano de fachada. Además con las plantas bajas libres, se consiguen relaciones no solo visuales, sino de paso, de conexión entre las diferentes unidades vecinales. (Fig. 3.17 y Fig. 3. 18)

Todo el conjunto adquiere unidad gracias a la materialidad hábilmente repetida en las diferentes tipológicas, pero con matices, especialmente en la utilización de los huecos de ventanas que se diferencian según la tipología de vivienda y, por lo tanto, del bloque al que pertenece.

Otras viviendas de $3^{\mathrm{a}}$ categoría se diseñan para el bloque lineal de cuatro niveles, orientado nortesur, en el que se resuelven las tipologías A4-3 de 75,97 m² construidos. La unidad se resuelve con un núcleo de escaleras, sin ascensor, que da servicio a dos viviendas con doble orientación. Los bloques quedan conformados por la adición
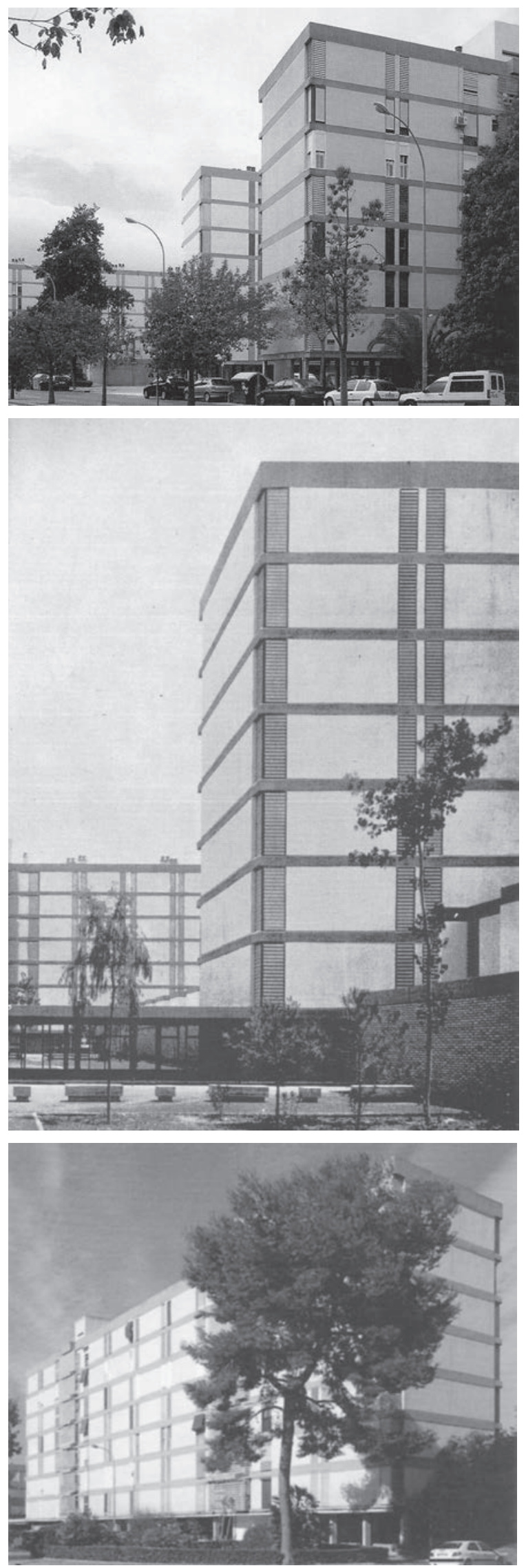

Figura 3. 16. Tipo A8-3, vista de las esquinas

Figura 3. 17. Tipo A8-3, vista de la unidad 
mayoritaria de cinco de estas unidades, pero también, para permitir su adaptación a las irregularidades del solar, con la adición de cuatro en el sector al norte y tres o dos unidades en el sector sur, adaptándose así a la oblicuidad del vial respecto a la ordenación ortogonal del sector. (Fig. 3.19)
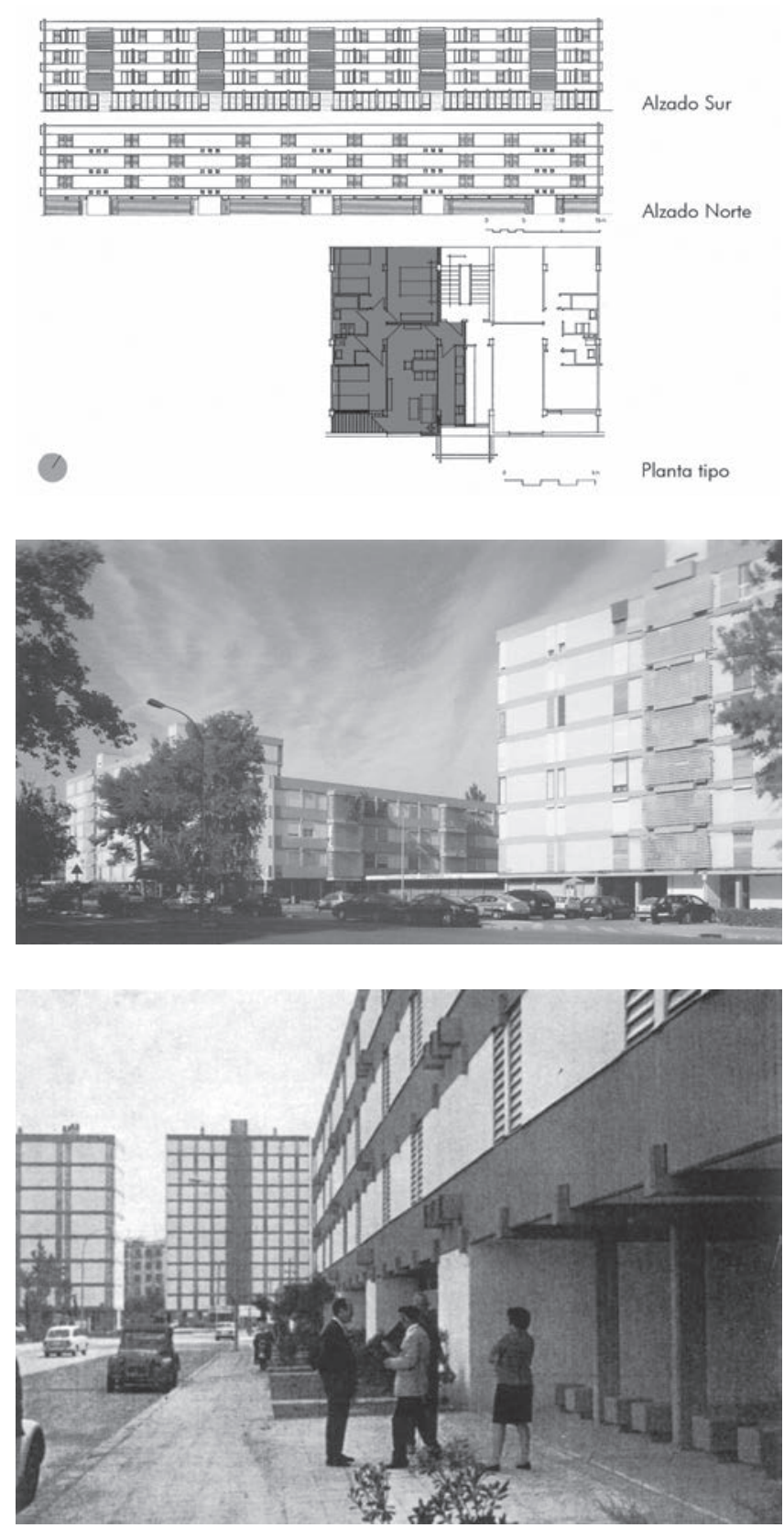

bargo, la planta baja no queda colmatada sino que se procede a dejar libre una de las crujías estructurales para lograr atravesar el bloque sin tener que rodearlo. (Fig. 3.20 y Fig. 3.2I)

Ubicándose en el centro de cada Unidad Vecinal, aparece el entramado formado por pasajes y viviendas unifamiliares adosadas que conforman la denominada "casbah cartesiana". Su formalidad equivale a la de una placa horizontal hábilmente estructurada, perforada por vacíos, que en ocasiones son huecos propiamente dichos que iluminan las calles interiores 
$y$, en ocasiones, conforman los patios de las viviendas. El sistema de agregación queda conformado por una calle cubierta desde la que se accede a las unifamiliares distribuidas a cada lado. Su adición con dos, tres o cuatro calles permite adaptarse a los requerimientos dimensionales que cada Unidad Vecinal necesita. Además de introducir iluminación a las calles, los patios estructuran la forma de las viviendas dotándolos de la necesaria privacidad que esta tipología requiere en un entorno urbano. (Fig. 3.22 y Fig. 3.23)

La agrupación se desarrolla a partir de una tipología de vivienda, la denominada B2-3 de $2^{\text {a }}$ categoría con una superficie de $88,80 \mathrm{~m}^{2}$. Introducen una pequeña variación dimensional sobre ésta se obtiene la tipología A2-4 de $3^{\text {a }}$ categoría y una superficie de $90,80 \mathrm{~m}^{2}$ con un dormitorio más en planta baja aunque resta sustancialmente superficie al salón. El programa se divide en función de la privacidad, situándose el salón-comedor, la cocina y un aseo en planta baja. Éstos obtienen ventilación e iluminación a través de su propio patio. En la planta superior se sitúan el baño y tres dormitorios, dos de los cuales se iluminan a través de su propio patio, y el tercero a través del patio que además dota de iluminación a la calle peatonal semicubierta. (Fig. 3.24 y Fig. 3.25)

La materialidad se resuelve segun las leyes de los anteriores
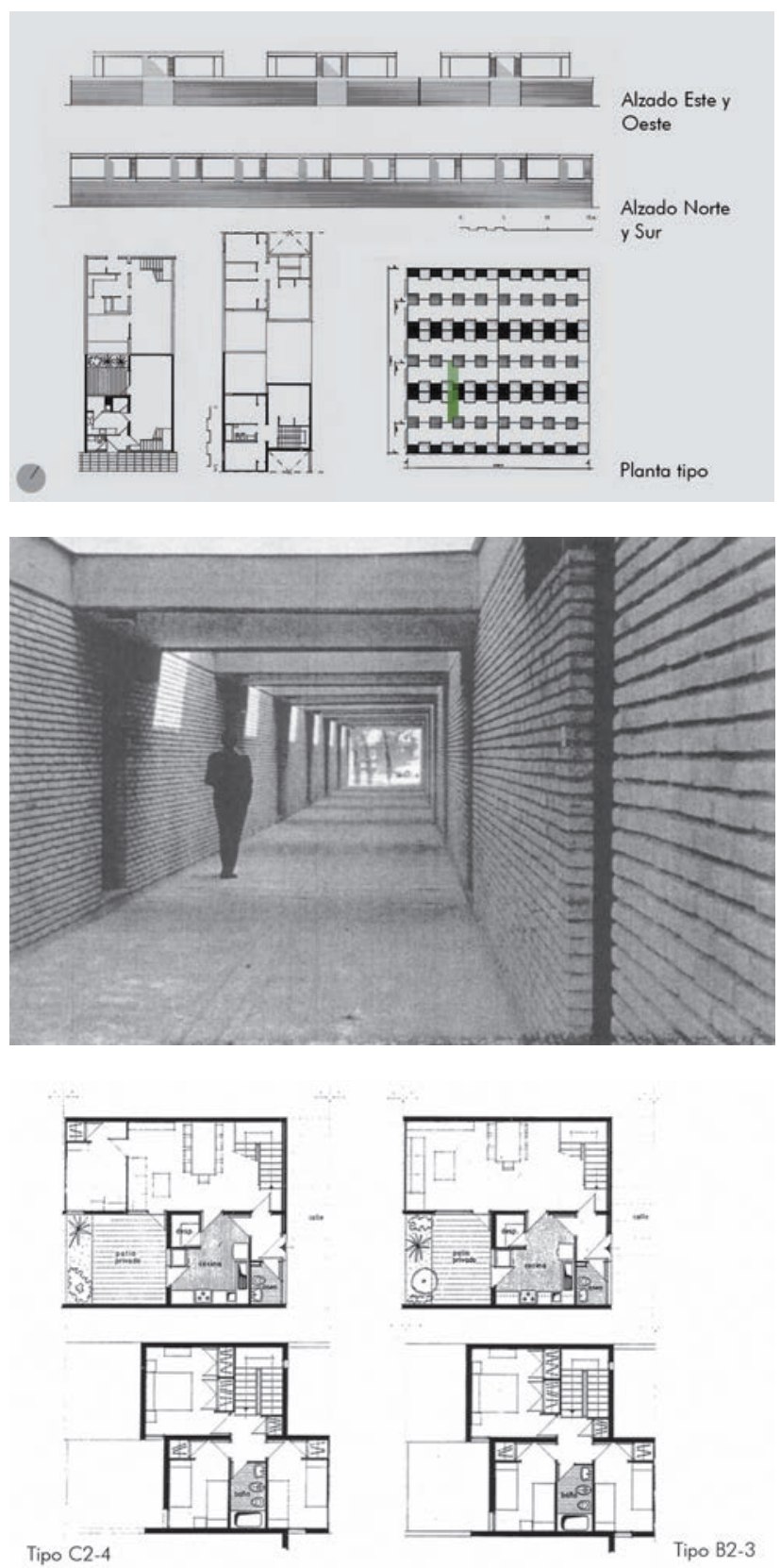

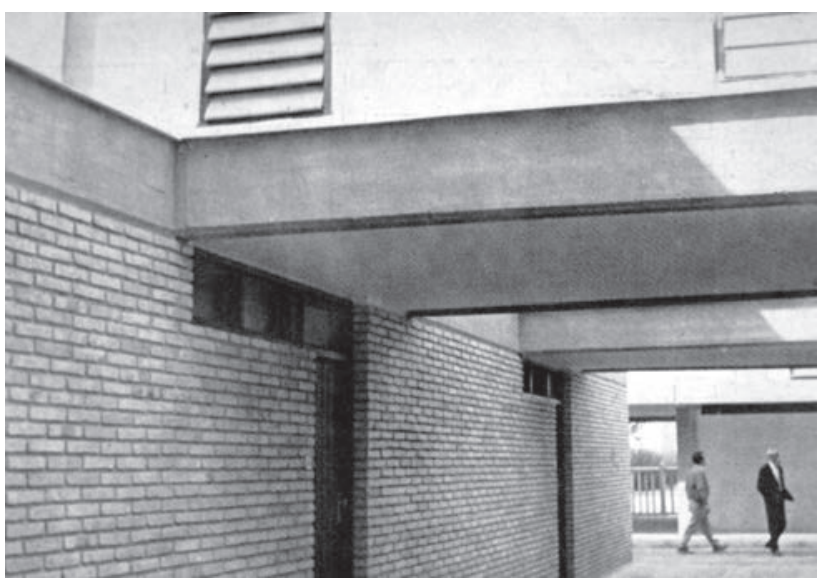

Figura 3.23. Tipo B2-3, vista de la calle interior con la alternancia de patios

Figura 3.24. Tipo B2-3 y B2-4, plantas

Figura 3.22. Tipo B2-3, planta tipo y alzado

Figura 3.25. Tipo B2-3, vista de la calle interio y de los huecos de los dormitorios 
Figura 3.26. Tipo B2-3, vista desde la plaza de la Unidad Vecinal

Figura 3.27. Tipo Cl2-4, planta tipo, portería y alzados edificios incorporan el ladrillo cara vista como envolvente principal que recorre la planta baja de los cerramientos exteriores. Se recurre nuevamente al hueco estrecho protegido por lamas en los dormitorios y reconocer la diferencia de forjados, el resto es de huecos amplios y acristalados que permiten introducir una iluminación adecuada. (Fig. 3.26)

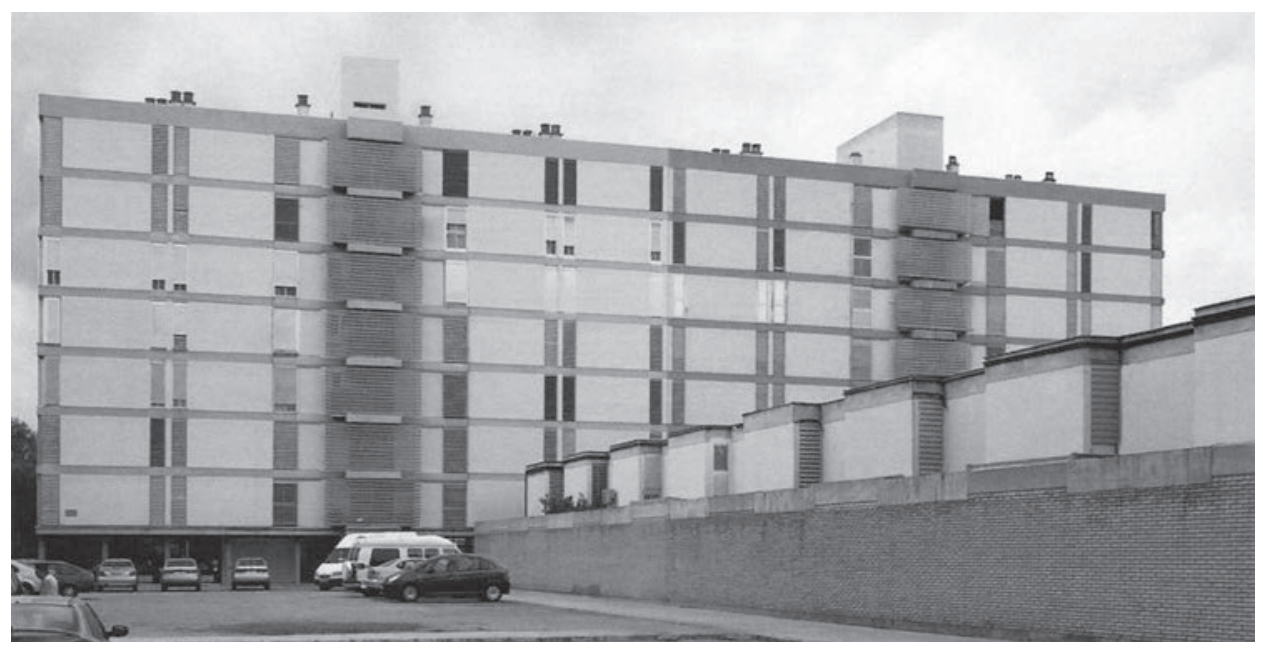

La la categoría de viviendas fue la desarrollada en las dos torres de 12 niveles situadas en el sector más oriental. La planta se compone por un núcleo de escaleras y dos ascensores que sirven a dos viviendas por nivel. La tipología CI2-4 de 140, I4 m² compone su programa cuidosamente ordenado al relacionar las particiones interiores con la pauta estructural. La estructura queda de nuevo retirada del plano de fachada lo que permite componer la libremente. Se incorpora el elemento de terraza, sobre la que vuelca el salón-comedor, que consigue romper el plano de fachada con su penetración y caracteriza a las viviendas con un espacio de transición entre el interior y el exterior. Se incorpora una zona de servidumbre compuesta por dormitorio y baño anexa a la cocina, para la incorporación de personal de servicio en la vivienda. (Fig. 3.27 y Fig. 3.28)
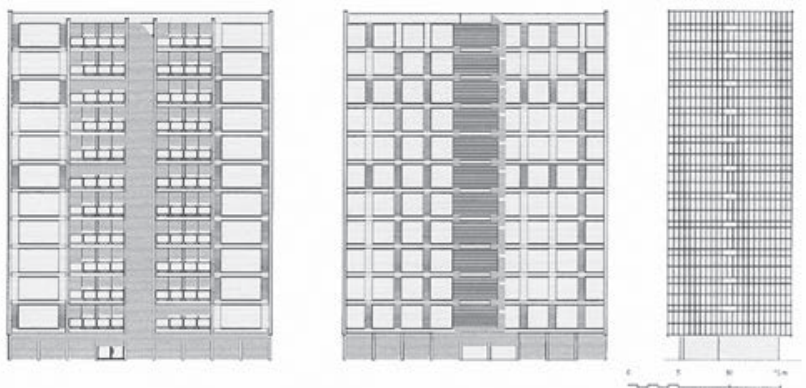

\author{
Alzado Este \\ Alzado Oeste \\ Alzado Sur y Norte
}

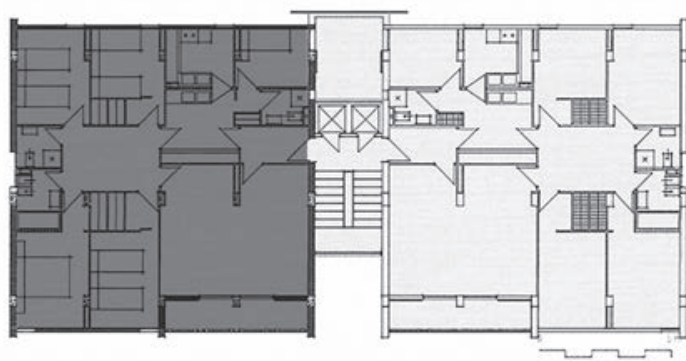

Planta tipo 


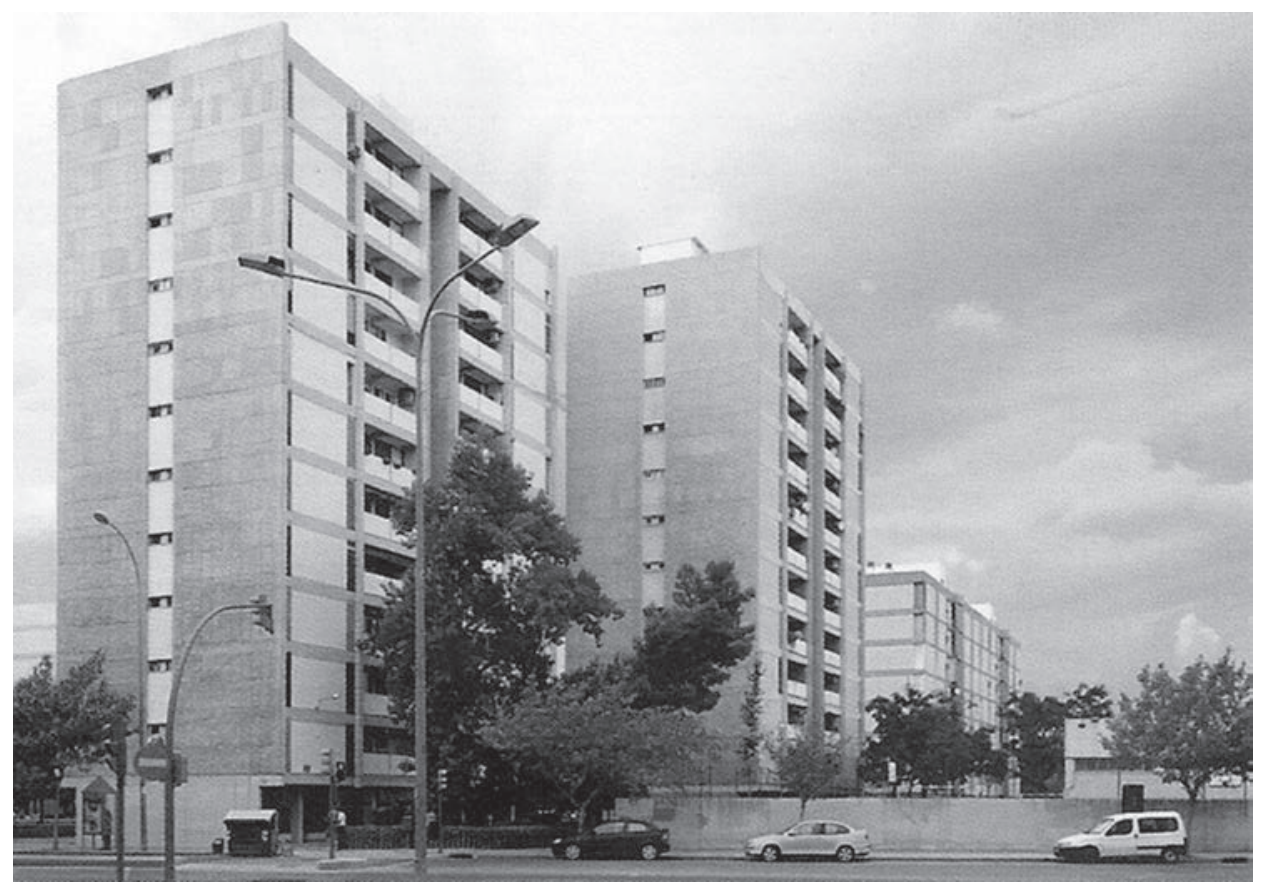

Las torres se materializan con los mismos principios de los bloques lineales, rompe la verticalidad con los cantos de forjados que quedan pautados por la estrechez de los huecos que se corresponden con cocinas y dormitorios y las celosías de lamas horizontales que recorren de modo continuo la zona de tendederos al oeste. Al este la fachada se interrumpe al retirarse la escalera del plano de fachada se intercala así un vacío entre cada vivienda. Los testeros, cierran la envolvente, perforados exclusivamente por los huecos de los baños que quedan recogidos en una banda vertical que introduce un cambio material. (Fig. 3.29 y Fig. 3.30)
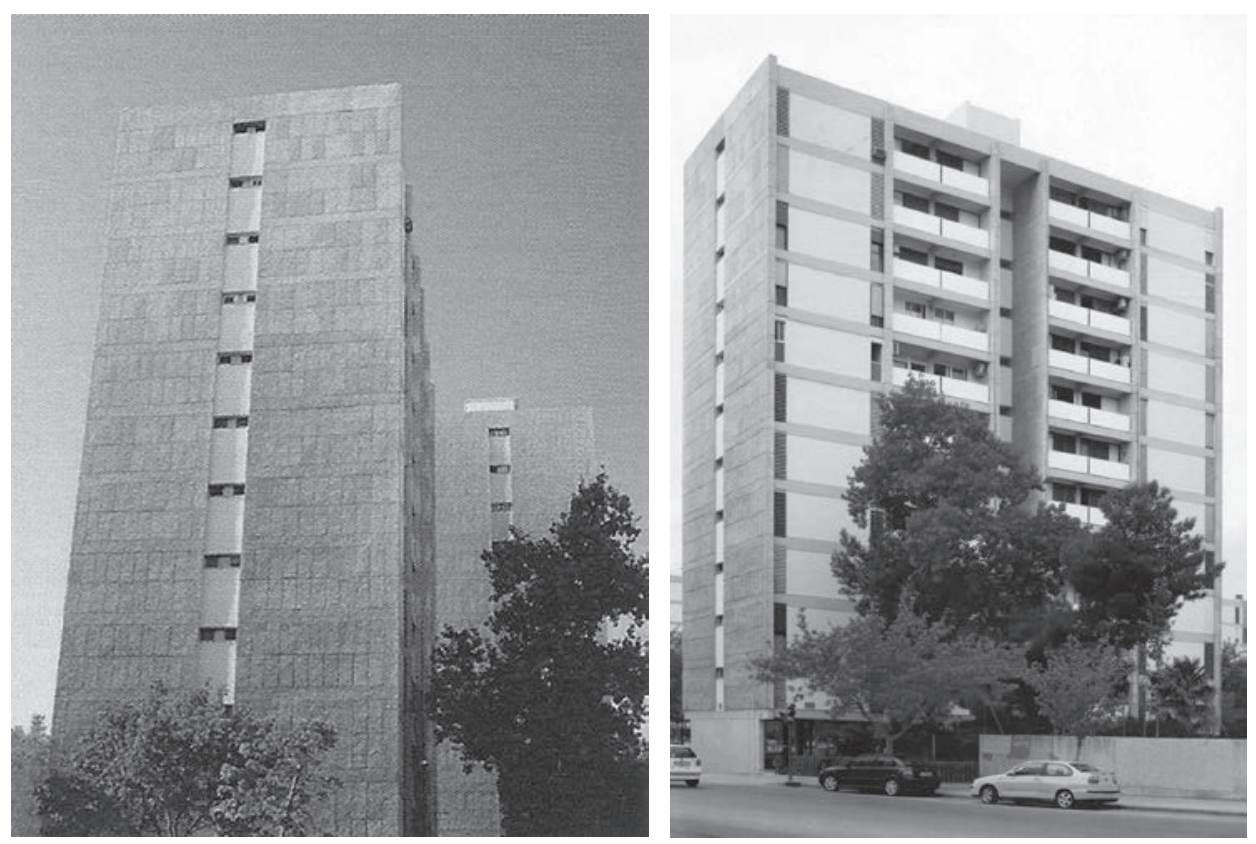

Figura 3.28. Tipo C/2-4, vista exterior de las dos torres

Figura 3.29. Tipo Cl2-4, vista del alzado lateral

Figura 3.30. Tipo Cl2-4, vista del alzado frontal 


\section{CONCLUSIONES}

Figura 3.3I. Vista de la Unidad Vecinal. Foto: A. Martínez, 2008

Figura 3.32. La plaza de la Unidad Vecinal. Foto: A. Martínez, 2008

Figura 3.33. La plaza de la Unidad Vecinal. Foto: A. Martínez, 2008
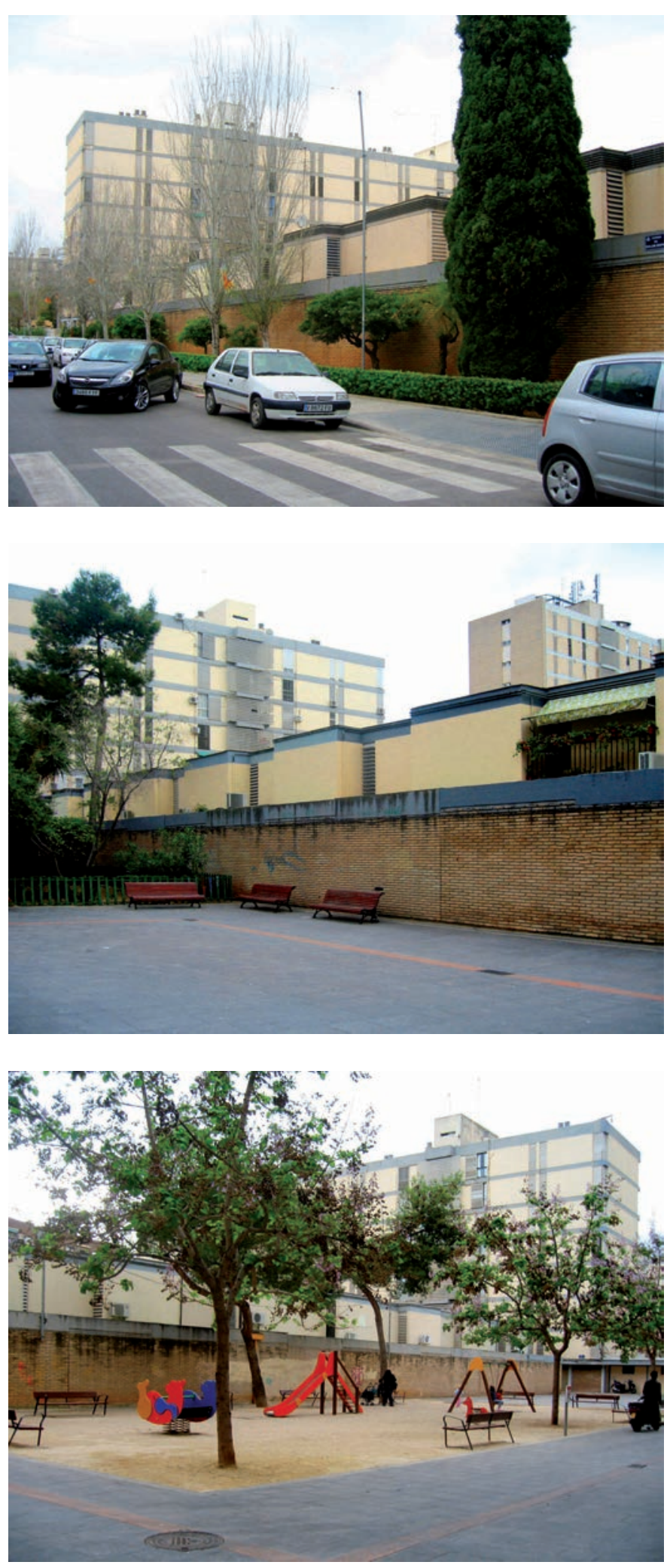

A nivel urbano, por su implantación en el territorio, es decir, por dónde y cómo se genera un determinado modelo de ciudad y por la relación con la ciudad existente, establecida por los vínculos y relaciones a través de un sistema primario en el que se tiene en cuenta la accesibilidad y la movilidad, y un sistema más complejo en el que se crea un tejido de continuidad e integración con la ciudad en la que se inserta. (Fig. 3.31 y Fig. 3.32)

16 Piñón, Helio. Teoría del Proyecto. Barcelona: Col.leció d'Arquitectura, Edicions UPC, 2006 
A nivel del conjunto, destacaría por el estudio de una unidad de agrupación, llamada por sus autores "Unidad Vecinal", capaz de dar una escala de mayor proximidad $y$, por lo tanto, de "barrio" a sus habitantes a la vez que una mejor gestión de su mantenimiento. Se plantean equipamientos básicos (escuela, guardería, parroquia) y comerciales capaces de resolver las necesidades más esenciales de sus habitantes y pese a que no todos llegaron a ejecutarse el Grupo ha quedado suficientemente abastecido. (Fig. 3.33 y Fig. 3.34)

\section{El grupo Antonio Rueda,} es un ejemplo de compromiso con los postulados del Movimiento Moderno en lo referente a la concepción de cómo se tenía que entender la planificación de los nuevos asentamientos para la vivienda social, incorpora una combinación de edificaciones en altura de diferentes formas y niveles con geometrías de carácter extendido. Además, el análisis realizado con diferentes categorías de viviendas permite resolver tipologías adaptables a los diferentes marcos sociales que evita así la transformación del conjunto en un gueto social. (Fig. 3.35 y Fig. 3.36)

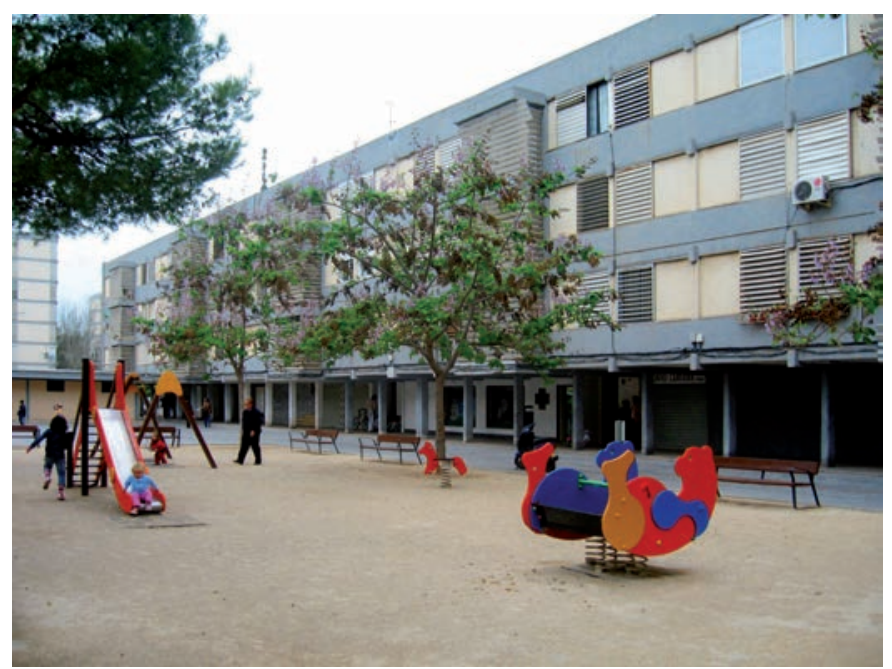

Figura 3.34. La plaza de la Unidad Vecinal Foto: A. Martínez, 2008
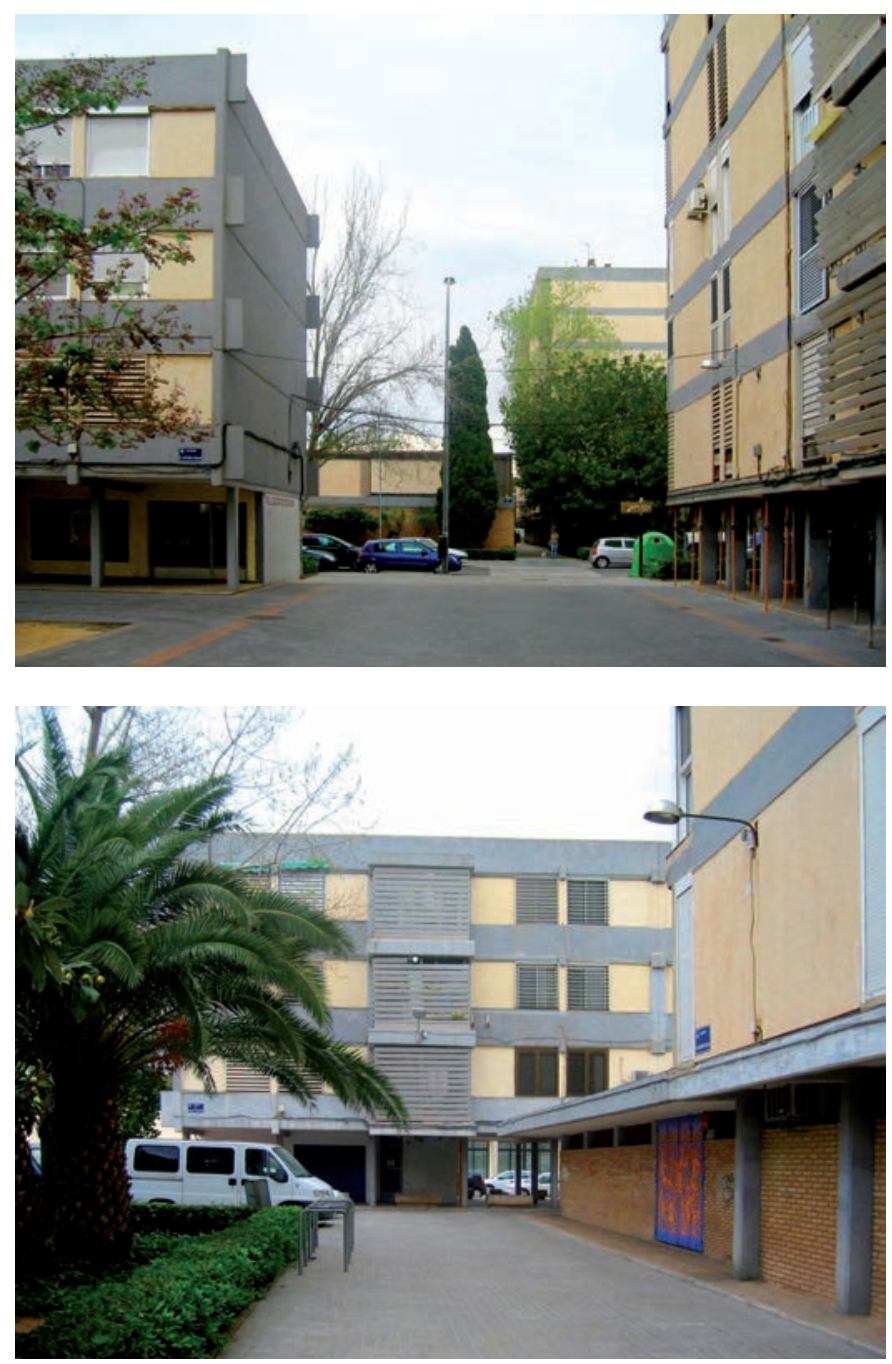

Figura 3.35. Los porches y comercios Foto: A. Martínez, 2008
Figura 3.36. Los porches y comercios Foto: A. Martínez, 2008

A un nivel más preciso se recurre a una serie de intenciones de proyecto como son la existencia en un control en el juego de las escalas y las proporciones de cada unidad y sus volúmenes para conformar un conjunto unitario pero variado, con una escala humana. Se dota intencionadamente al conjunto de unidad, caracterizándolo por una serie de rasgos 
Figura 3.37. La calle semi-cubierta de las viviendas unifamiliares. Foto: A. Martínez, 2008

Figura 3.38. La calle semi-cubierta de las viviendas unifamiliares. Foto: A. Martínez, 2008 comunes a todos los edificios gracias al control efectuado sobre la planta, la abstracción de los diferentes planos de fachada y las soluciones singulares de sus esquinas. La utilización de una pauta estructural, el módulo regulador, se utiliza como un elemento de diseño básico, capaz de generar ritmo y orden a la vez que permite dar una correcta respuesta al programa requerido. La utilización de porches se utiliza como diafragma entre el interior y el exterior.

Por todo ello el conjunto adquiere en la actualidad la calidad y vigencia suficiente para formar parte de la memoria del que proyecta como "material de proyecto", es decir, como "aquellos elementos, criterios o soluciones, pertenecientes a la experiencia propia o ajena, que constituyen la materia prima a la que el sentido del orden de quien proyecta conseguirá dotar de estructura formal (...)"'17. Y en este sentido cobran valor las palabras de Mies: "creo que la arquitectura poco, o nada, tiene que ver con la invención de formas interesantes, ni con preferencias personales [...] siempre es objetiva y es la expresión de la estructura interna de la época."

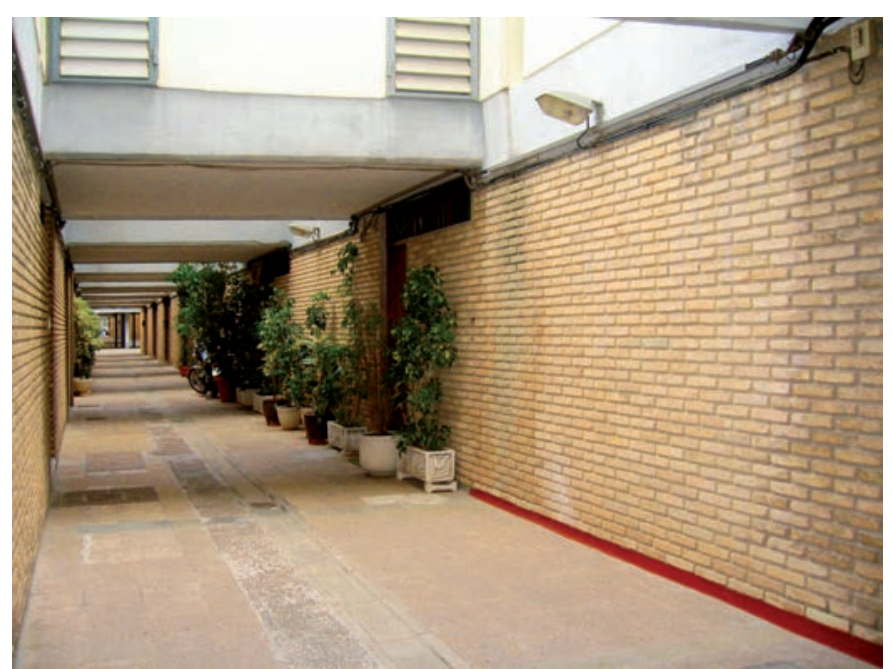

El conjunto ha sabido sobrevivir el paso del tiempo y su estado actual y conservación se debe fundamentalmente a la labor de la asociación de vecinos, que han sabido valorar los aspectos que sus arquitectos infundieron en el proyecto, como podemos comprobar a través de las imágenes actuales que han acompañado intencionadamente a este texto. El paso del tiempo ha ocasionado pequeños

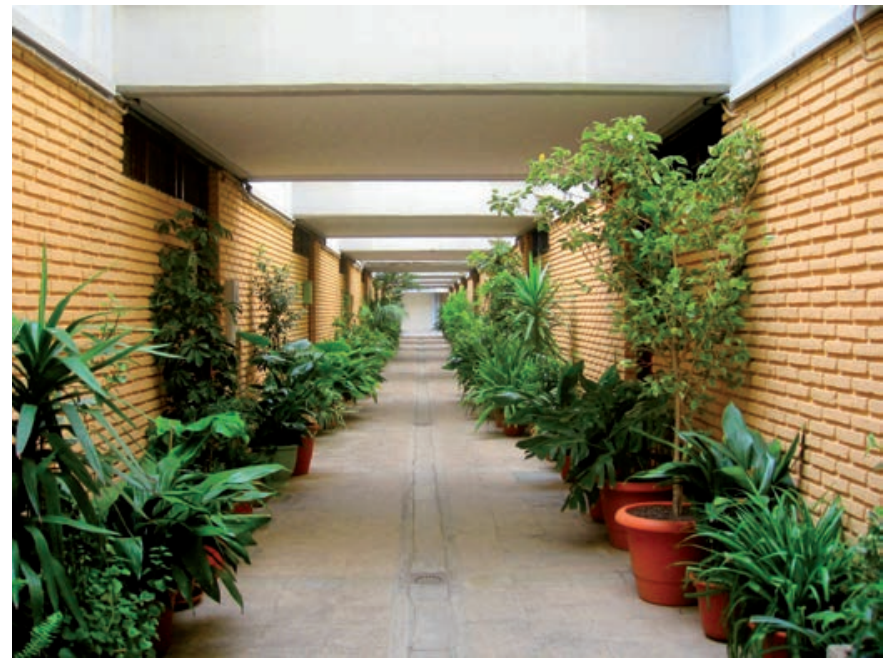
cambios como la sustitución, en algunos casos de las lamas exteriores, lo que no deja de ser un hecho aislado para reconocer el valor del Grupo. Pero cabría añadir una objeción y es que el aumento del uso del automóvil y, por lo tanto, del parking automovilístico de sus habitantes no fue considerado, por lo que el conjunto adolece en la actualidad de las necesarias áreas de aparcamiento que podrían haber sido subsanadas con un aparcamiento bajo superficie, pero no podemos obviar un hecho y es que, eran otras épocas. (Fig. 3.37 y Fig. 3.38)

17 . Piñón, Helio. Teoría del Proyecto. Barcelona: Col.leció d’Arquitectura, Edicions UPC, 2006 
El Grupo “Antonio Rueda” recibió Mención por el Colegio de Arquitectos de Valencia en 1973 y Vicente Valls Abad, uno de sus autores, fue nombrado en 2004 Mestre Valencià d'Arquitectura por el Colegio Oficial de Arquitectos de la Comunidad Valenciana en reconocimiento a su trayectoria profesional. (Fig. 3.39)

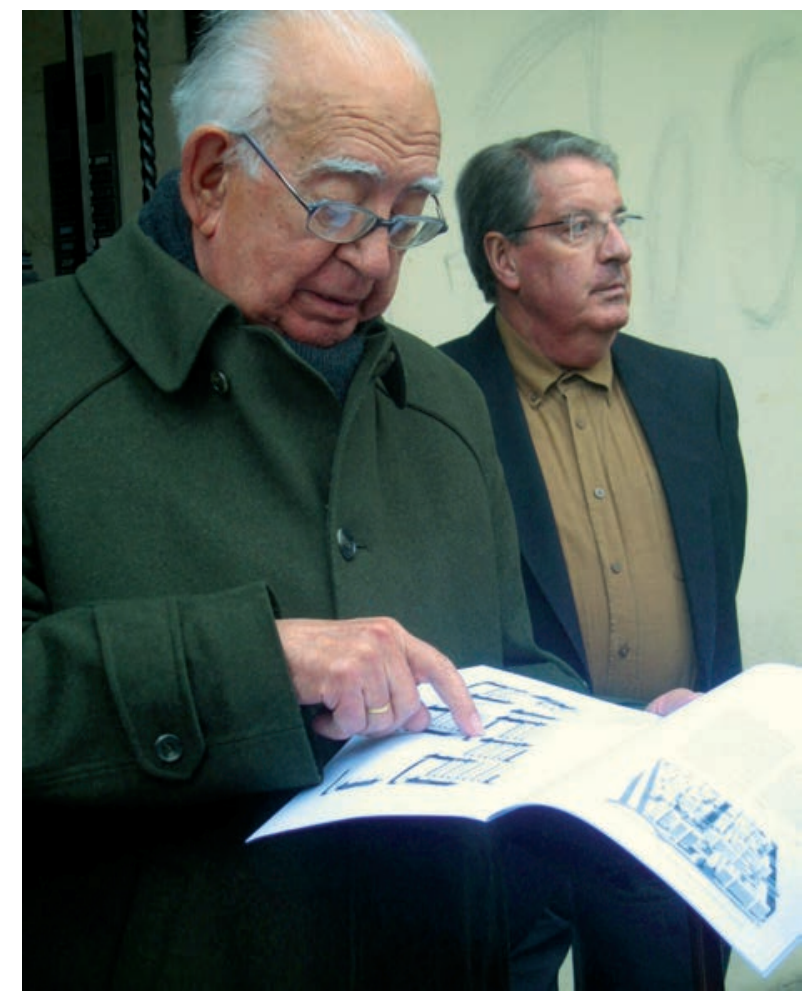

\section{BIBLIOGRAFÍA}

BERGERA, Iñaki “O.S.H: tres décadas de vivienda social”, y VAZ, Celine "Una década de planes: planificación y programación de la vivienda de los años cincuenta”. En SAMBRICIO, Carlos (ed). La vivienda protegida, historia de una necesidad. Gobierno de España, Ministerio de vivienda \& AVS, 2010

COLOMER, Vicente (coord.). Registro de Arquitectura del siglo XX. Comunidad Valenciana. 2 vols. Valencia: COACV, COPUT de la Generalitat Valenciana e Instituto Valenciano de la Edificación, 2002

FERNÁNDEZ-GALIANO, Luis; F. Isasi, Justo; Lopera, Antonio. La quimera moderna. Los Poblados dirigidos de Madrid en la arquitectura de los 50. Madrid: Hermann Blume, 1989

GAJA, Fernando. La promoción pública de la vivienda en Valencia, 1939-1976. Valencia: Consellería d'Obres Públiques i Tansports, 1989

GROPIUS, Walter. Internationale Architektur. Munich: Bauhaus Bücher, A. Langen, 1925

HOFFMANN, Julius, Die wohnungtur das Existenz Minimum, Suttgart, 1929
Figura 3.39. El arquitecto V. Valls y el aparejador J. García Valdecabres en la visita realizada al Grupo Antonio Rueda, organizada por ICARO-CTAV. Foto: A. Martínez, 2008 
JORDÁ, Carmen. 20x20. Siglo XX. Veinte obras de arquitectura moderna. Catálogo de la Exposición. Valencia: Ed. Generalitat Valenciana, COPUT y COACV, 1997

JORDÁ, Carmen (ed.). Vivienda Moderna en la Comunidad Valenciana. Exposición y catálogo. Valencia: CMAAUH y COACV, COACV, 2007; pp. 230-235

LE CORBUSIER. Hacia una Arquitectura. Barcelona: Ed. Apóstrofe S.L., 1998. [Vers une architecture, 1923.]

LLOPIS, Amando; Dauksis, Sonia (ed) Arquitectura del siglo XX en Valencia. Seminario Mayo 2000. Colección Formas Plásticas n9. Valencia: Ed. Institució alfons el Magnànim, Diputació de València, 2000. p. II 8

MOYA, Luis., (2003): "Los Polígonos de Vivienda". En SAMBRICIO, Carlos (coord.). Un siglo de Vivienda Social (1903-2003) Madrid: Ed. Ayuntamiento de Madrid, Mº Fomento y CES, 2003

PALOMARES, María Teresa. La producción experimental de GO.DB Arquitectos. (Directora: Carmen Jordá Such). Valencia: UPV, 2010. [Biblioteca de la Universidad Politécnica de Valencia-UPV]

PEÑíN, Alberto. Valencia. 1874-1959. Ciudad, Arquitectura y Arquitectos. Valencia: Ed. ETSAV, 1978

PIÑÓN, Helio. Teoría del Proyecto. Barcelona: Col.leció d’Arquitectura, Edicions UPC, 2006

SAMBRICIO, Carlos (ed.). Un siglo de vivienda social: 1903-2003. Madrid: Nerea, 2003

SAMBRICIO, Carlos. Madrid, vivienda y urbanismo: 1900-1960. Madrid: Ediciones Akal, 2004

TABERNER, Francisco. Guía de Arquitectura de Valencia. Valencia: CTAV, 2007. p. 2 I4

\section{REVISTAS}

“Poblado de Caño Roto". En Revista Nacional de Arquitectura No. I76-I77 (I 956): pp. 56-57.

“Poblado Dirigido de Caño Roto”. En Arquitectura, 8 (Agosto 1959): pp. 2-17

L'Architecture d'Aujord'hui, 85 (Septiembre 1959): pp. 2-17

Werk 49/06 (1962): pp. 195-197

GARCÍA, F.M.; Dexeus, J.Ma. "Grupo de viviendas Virgen del Carmen, Valencia" en Informes de la construcción, 149. Ed. Instituto Eduardo Torroja (1963): p. 25

"Poblado de Caño Roto (3a fase), Madrid." En Hogar y Arquitectura, 54 (1964): pp. 2-7

"Poblado Dirigido de Caño Roto ( ${ }^{\mathrm{a}}$ y $2^{\mathrm{a}}$ fase), I 1.606 viviendas." En Hogar y Arquitectura, 54 (1964): pp. I2-34 
FLORES LÓPEZ, C.”El poblado de Caño Roto.” En Hogar y Arquitectura, 54 (1964): pp. $35-38$

Zodiac, 15 (Diciembre 1965): pp. 120-30

Aujord'hui Art + Architecture No.52, Febrero 1965; p. 64

"Polígono de Vistabella en Murcia. Grupo "La Paz", de I.502 viviendas de tipo social." En Hogar y Arquitectura, 67 (1966): pp. 2-6

Baumeister, (Junio 1967): pp. 718-72I

"La vivienda social en España a través de cien números de Hogar y Arquitectura". En Hogar y Arquitectura, 100 (1972)

“Grupo "Antonio Rueda” de I.002 viviendas en Valencia." En Hogar y Arquitectura, 106 (mayo-junio 1973): pp. 2-16

"La Obra Sindical del Hogar". En Cuadernos de Arquitectura y Urbanismo, 105 (1974)

"Realizaciones de la OSH: Valencia." En Hogar y Arquitectura, I2I (mayo-junio 1977): pp. 68-79 